\title{
The morphology of the last instar larva of Aglaope infausta (Lepidoptera: Zygaenidae: Chalcosiinae)
}

\author{
HARALD FÄNGER and CLAS M. NAUMANN \\ Zoologisches Forschungsinstitut und Museum Alexander Koenig, Adenauerallee 160, 53113 Bonn, Germany; \\ e-mail: h.faenger.zfmk@uni-bonn.de
}

Key words. Zygaenidae, Aglaope infausta, larva, morphology, histology, chaetotaxy

\begin{abstract}
The larval morphology of the western Palaearctic zygaenid species Aglaope infausta (Linnaeus, 1767) is described and figured in detail. Unlike other members of the zygaenid subfamily Chalcosiinae, the last instar larva of $A$. infausta has numerous secondary setae and a multitude of cuticular cavities that are devoid of openings. The other chalcosiine genera have primary setae and cuticular cavities with specialized openings through which a defensive secretion can be discharged. Imaginal characters, on the other hand, provide strong evidence for placing Aglaope in the Chalcosiinae.
\end{abstract}

\section{INTRODUCTION}

The composition of the ditrysian moth family Zygaenidae has changed considerably over the years and is still in a state of flux. In 1954, Alberti, the pioneer of zygaenid systematics, recognized seven subfamilies, the Anomoeotinae, Chalcosiinae, Charideinae, Himantopterinae, Phaudinae, Procridinae, and Zygaeninae. Subsequently, the Charideinae were transferred from the Zygaenidae to the Thyrididae (Minet, 1991), and both the Anomoeotinae and Himantopterinae were raised to family rank by Fletcher \& Nye (1982). Likewise, the Phaudinae will probably have to be excluded from the Zygaenidae (Fänger et al., 1999), since they obviously share a number of apomorphic characters with the families Aididae, Dalceridae, Limacodidae, Megalopygidae and Somabrachyidae, together with which they form a large clade within the Zygaenoidea for which the informal term limacodid group has been proposed (Epstein, 1996). Furthermore, the isolated South East Asian genus Callizygaena Felder, 1874, was transferred from the Procridinae to the newly established subfamily Callizygaeninae (Tarmann, 1994), whose inclusion in the Zygaenidae still remains to be verified. In essence, four subfamilies, the Chalcosiinae, Procridinae, Zygaeninae and tentatively the little-known Callizygaeninae are currently recognized as zygaenids.

Although some potential autapomorphies for the Zygaenidae have been suggested (Naumann et al., 1999: 14), the present concept of the family must still be considered provisional, since it cannot be ruled out with certainty that the genera Heterogynis Rambur, 1837, and Janseola Hopp, 1923, united in the family Heterogynidae by Scoble (1992), will also have to be included. Likewise, the placement of the Lactura-group of genera, long regarded as yponomeutids, has never been unequivocally established. Provisionally assigned to the Zygaenidae (Kyrki, 1984), the new family Lacturidae has recently been formally established for this group (Heppner, 1995).
The zygaenid subfamily Chalcosiinae Hampson, (1893), comprising some 300 species, is restricted to the eastern Palaearctic and Indo-Australian regions, the western Palaearctic genus Aglaope Latreille, 1809, being a remarkable exception (Alberti, 1954; Naumann et al., 1999). Two potential autapomorphies of the subfamily, both confined to the adult stage, are currently recognised: in males, the scent brush near each posterior hindwing base, and in females, the telescopic oviposition-tube formed by the terminal abdominal segments (Tarmann, 1992; Epstein et al., 1999). Five tribes are distinguished, the isolated genus Aglaope being the sole member of the Aglaopini (Alberti, 1954). Only two species are known, A. infausta (Linnaeus, 1767) from south-western Europe and $A$. labasi Oberthür, 1922, from Morocco (Naumann et al., 1999). A further species, originally described as $A$. fasciata Felder \& Felder, 1862, has recently been transferred to a new genus, Pseudopidorus (Yen \& Yang, 1997). Generally, the larval morphology of chalcosiine species is poorly documented, although recently two representatives of the tribe Chalcosiini have been described in some detail (Yen \& Yang, 1997, 1998).

Therefore, as a contribution towards a better-founded concept of the subfamily Zygaenidae, a comprehensive account of the larval morphology of A. infausta is presented in this paper.

\section{MATERIAL AND METHODS}

Penultimate instar larvae of A. infausta, feeding on Prunus spinosus (Rosaceae), were collected in May 1998 in the central Rhine valley of Germany. In the laboratory they were kept in small plastic boxes and fed fresh leaves of the foodplant.

For histological investigations, last instar larvae, killed by exposing them to ethyl chloride vapour, were fixed overnight in alcoholic Bouin solution (modification after Dubosq Brasil) at $50^{\circ} \mathrm{C}$ and dehydrated in a graded series of ethanol. Some specimens were then embedded in Paraplast, and others in Spurr medium (ERL 4206 epoxy resin). The former were serially sectioned at $7 \mu \mathrm{m}$, stained according to the Azan procedure and mounted in euparal. The latter were serially sectioned at $1 \mu \mathrm{m}$ 
and stained in a solution of methylene blue and azure II aqueous borax. Details of the methods used are given in Romeis (1989).

To achieve maximum expansion of the body as well as eversion of both the head capsule and the prothoracic subventral tube, the remaining larvae were killed by immersing them in boiling water. Larvae treated in this way were stored in $70 \%$ ethanol and then processed in one of two ways:

1. To examine the chaetotaxy, several larvae were cut longitudinally, either along the dorsal or ventral midline. They were then placed in cold $10 \% \mathrm{KOH}$ for about two days and then the tracheal system was carefully removed before storing in $95 \%$ ethanol. The head capsules of some of these larvae were removed and studied separately. A number of larval specimens (or parts thereof) were later embedded in euparal and photographed.

2. Prior to SEM, some ethanol-fixed larvae were dehydrated in absolute ethanol, transferred to acetone, critical-point dried via carbon dioxide and finally sputter-coated with a thin layer $(20 \mu \mathrm{m})$ of gold. $\mathrm{KOH}$-treated specimens were less suitable for SEM studies.

The terms used to describe the larval morphology and chaetotaxy are those of Fänger et al. (1999). The morphological descriptions of the head capsule and its appendages assume an hypognathous orientation.

\section{RESULTS}

Pattern and coloration. Unlike the blackish and milky white earlier instars, the last instar larva of $A$. infausta, colour photographs of which are figured by Gómez de Aizpúrua (1991: 212-214) and Naumann et al. (1999: pl. 10, fig. 5), has a distinct pattern of conspicuously coloured longitudinal bands.

Head capsule (Figs 1-3, 18, 19, 32). The larval head capsule exhibits several specializations, most of which are correlated with the ability of larvae to retract their head into the prothorax. Mediodorsally, it is divided into two symmetrical hemispheres by a deep median incision, the epicranial notch. As a consequence, the paired adfrontal sutures, laterally defining the frontoclypeus, do not merge into a dorsomedian epicranial suture, but reach the lower tip of the epicranial notch separately. There are three pairs of cranial apodemes, probably originating from the fusion of the cranial cuticle with the recurrent neck membrane. Two of them, the dorsal and ventral occipital apodemes, are transparent, the lateral head apodeme is sclerotized like the remainder of the head capsule, rendering the determination of its exact outline difficult. The

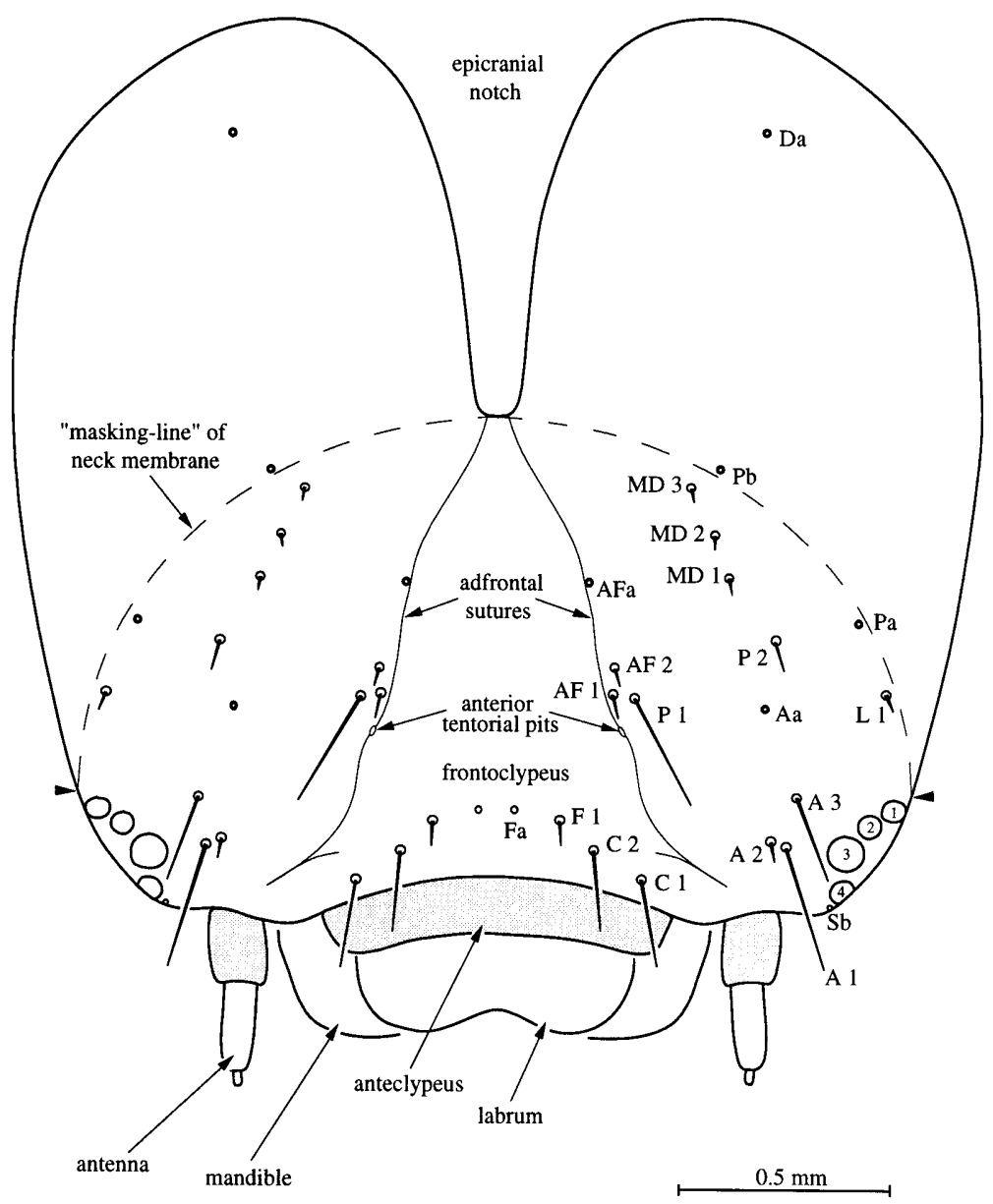

Fig. 1. Head capsule of last larval instar of $A$. infausta (Linnaeus, 1767), frontal view. The broken "masking-line" represents the recurrent rim of the elongate neck membrane, which tightly covers the head capsule. The neck membrane extends between the medial epicranial notch and the lateral head apodemes, the ventral tips of the latter being indicated by arrowheads. Pit-like, circularwalled cranial pores are represented by strong circles, while simple membranous cranial pores, which are level with the surrounding cuticle, are shown as weak circles. Four stemmata (1-4) are visible. The setae occurring on the cranial appendages are omitted. 
neck membrane above the "masking line", i.e. that part extending between the epicranial notch and the lateral head apodeme, covers the epicranium tightly and permanently. The six stemmata are arranged roughly in a circle, with stemma 5 displaced ventrally. The tentorium is represented by a pair of slender, rod-like apodemes crossing the head capsule antero-posteriorly. Posteriorly, the apodemes are linked with each other by a slender sclerotized bridge, the corpotentorium. A pair of irregularly shaped invaginations, situated on the adfrontal sutures some distance above the frontoclypeus, are sometimes discernible when using a SEM. These invaginations, which are not detectable under a light microscope, probably correspond to the anterior tentorial pits, marking the origin of the anterior tentorial arms.

Cranial chaetotaxy (Figs 1-3, 18, 20, 22, 23, 24, 25, 32 ). On the head capsule, there is a full complement of primary setae and pores, the relative positions of which are variable. The setae AF2, L1, P1, and P2, as well as the microsetae MD1-3 are clearly situated ventrally. Several setae, such as AF1, AF2, A2, F1, L1, and P2 are, in addition to their spatial dislocation, comparatively short.
As a consequence, the microsetal zone, i.e. the epicranial region of the head capsule on which only microsetae and pores are present, occupies a large proportion of the cranium. Under a dissecting microscope the membranous pores $\mathrm{Fa}, \mathrm{Sb}$, and $\mathrm{SSa}$ may be easily mistaken for microsetae, while the remaining pores $\mathrm{Aa}, \mathrm{AFa}, \mathrm{Da}, \mathrm{Ga}, \mathrm{La}, \mathrm{Pa}$, $\mathrm{Pb}$, and $\mathrm{Sa}$ are readily distinguished from microsetae by their heavily sclerotized bases. The sclerotized pore AFa is unusual in being hardly discernible against the dark background. However, its presence has been confirmed by SEM and its pit-like structure that is typical of the sclerotized type of pore. The cranial pores, in contrast to the setae, were found to have preserved a fairly conservative arrangement.

Antenna (Figs 4, 24, 26, 27, 32). The antenna arises from a prominent membranous base, which houses the antennal apodeme. The latter merges with antennal segment 1 , which is very short and largely retracted into the membranous base. The short antennal segment 2, which is connected with segment 1 via a short ring of membrane, broadens slightly toward its tip. On the outer surface the antenna bears a pore (ABa). Apically,

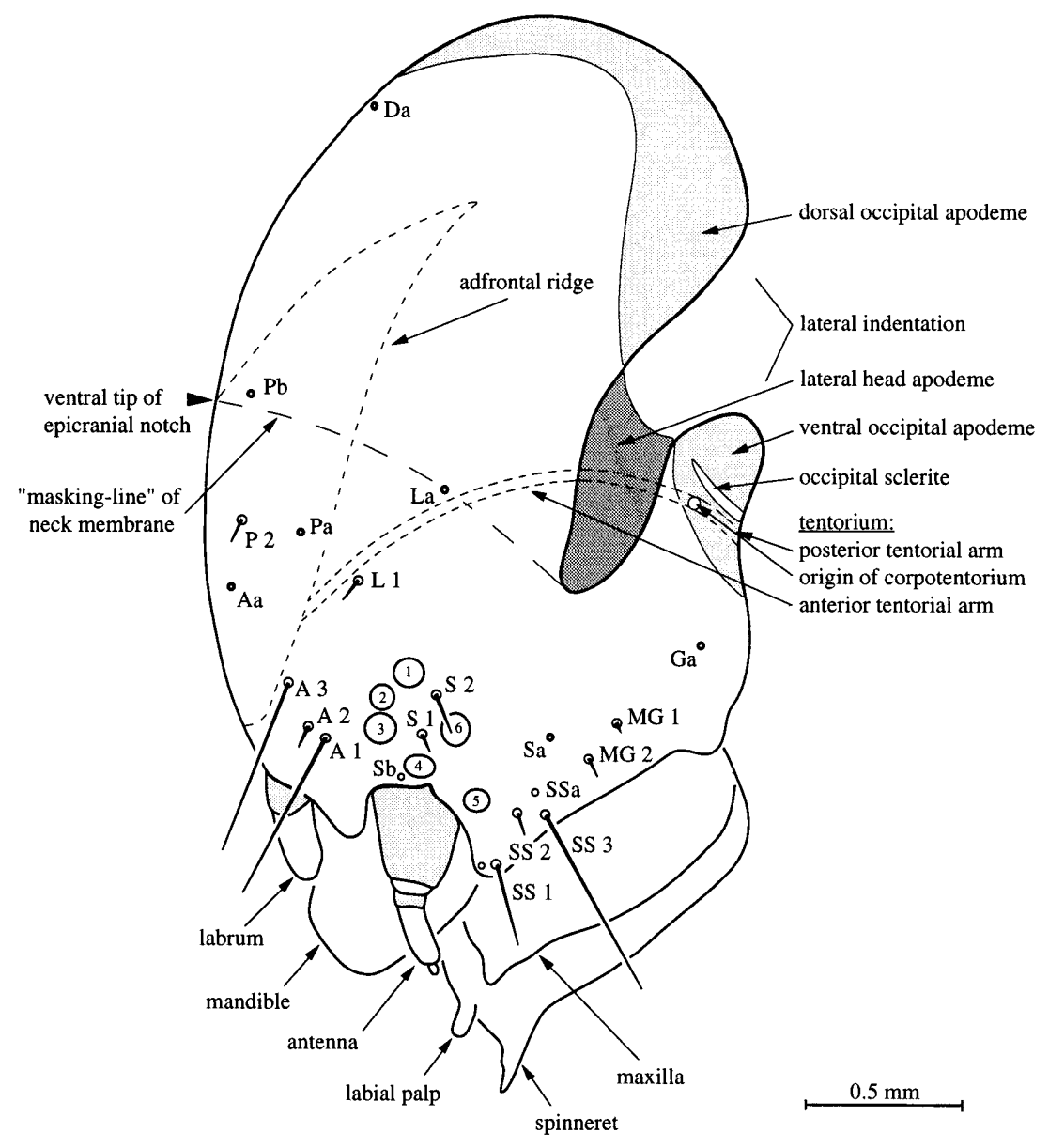

Fig. 2. Head capsule of last larval instar of $A$. infausta (Linnaeus, 1767), lateral view. The structures located inside the head capsule, the adfrontal ridge and tentorial arms are indicated by fine dashed lines, the "masking-line" of the neck membrane by a bolder dashed line. In order to delimit apodemal areas clearly, the dorsal and ventral occipital apodemes as well as the lateral head apodeme are depicted in lighter and darker shades of grey, respectively. Circles indicate the presence of pores, of which two types are distinguished. The antenna and mouthparts are shown without setae. 
antennal segment 2 terminates in a membranous disc bearing 5 setae of very different sizes and shapes (AB1-5) as well as a small cone. The terminal cone, representing antennal segment 3 , bears 4 setae (AC1-4). The styloconic mediodorsal seta $(\mathrm{AC} 1)$, around $35 \mu \mathrm{m}$ in length, is slightly longer than both the cone-shaped median seta $(\mathrm{AC} 2)$ and the slender ventrolateral seta (AC3). The dorsolateral seta (AC4) is the shortest.

Labrum (Figs 5, 28, 29, 32). The labrum is slightly indented medioventrally. Its anterior surface, sclerotized only in the dorsal half, bears six setae (AL1-6) on either side. Two setae, AL2 and AL6, are considerably shorter than the remaining setae. The anterodorsal sclerotization of the labrum extends into a lateral pair of medially curved arms, which probably serve to stiffen the labral opening in order to maintain a free passage of haemolymph, nerves and tracheae. Owing to the overall low level of melanism/sclerotization, membranous pores could not be detected with certainty. The posterior labral surface, the epipharynx, is membranous throughout. Its medial surface is covered with medially and dorsally directed spinules. The epipharynx bears three flattened, appressed setae (PL1-3) and two sensilla campaniformia (PLa, PLb) on either side. Even when viewed by SEM the spherical, button-like sensilla campaniformia are fairly inconspicuous, since their bases are hardly set off against the surrounding epipharyngeal surface.

Mandibles (Figs 6, 30, 31). The strongly sclerotized mandibles, which often showed considerable wear, bear four cusps (II-V), of which the anterior cusp (I) is much reduced. On the outer posterior surface two setae (LM1, LM2) are present near the condyle of the posterior joint. The cup-shaped inner mandibular surface is characterized by the presence of a rounded basal elevation. A deep pit, probably representing the opening of the mandibular gland, is regularly found subapically between cusps III and IV on the inner mandibular surface. The anterior and posterior joints, as well as the outer and inner apodemes are typically developed.

Labio-hypopharyngeal complex (Figs 3, 32, 33). The anterior surface of the unpaired complex is largely smooth, the occurrence of spinules being confined to the proximal region. On the posterior surface of the complex, two sclerotized plates, the submentum and prementum, are present. A pair of setae (LA1) is found in the unsclerotized medial region, where the mentum is found in most species. The submentum is synscleritous with the cardo, which is, however, commonly considered to be part of the maxilla (see below). The prementum is distally preceded by a pair of lateral sclerotizations, in front of

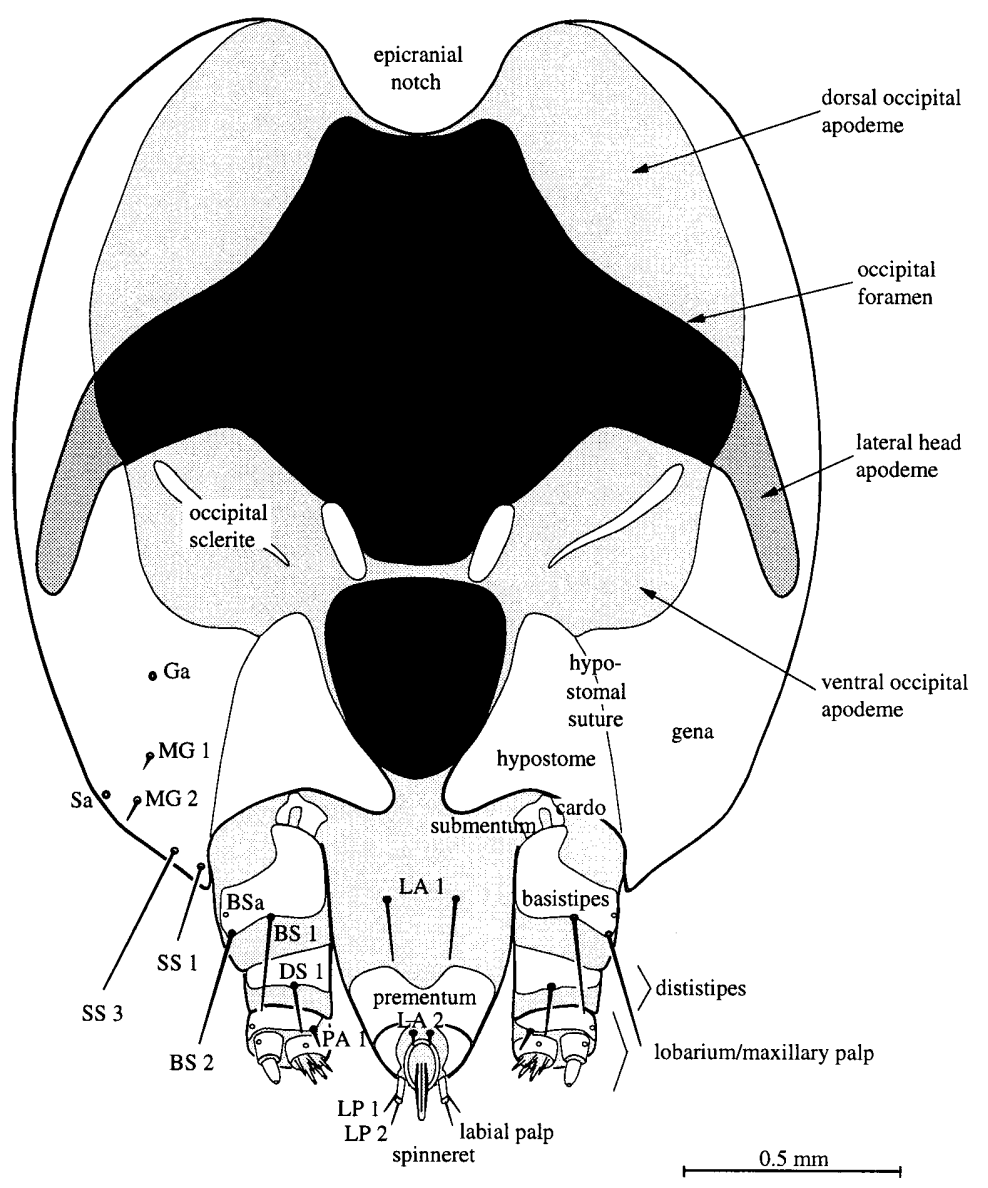

Fig. 3. Head capsule of last larval instar of $A$. infausta (Linnaeus, 1767), posterior view. The occipital foramen, connecting the lumina of the head capsule and the trunk, is coloured black. Like the membranes, the dorsal apodemal areas are depicted by grey coloration. Circles indicate the presence of pores, of which two types are distinguished. 
which the labial palpi are situated. The latter bear a sensillum trichodeum (LP1) subapically and a sensillum styloconicum (LP2) apically. The distal part of the complex is provided with a slender spinneret, which bears the salivary gland opening. The spinneret is encircled by a narrow ring-like sclerotization. Above/behind this ring a pair of short setae (LA2) is present between the pair of lateral sclerotizations.

Maxillae (Figs 3, 32, 34, 35). Like the labiohypopharyngeal complex the paired maxillae, arising basolaterally from the labio-hypopharyngeal complex, are subdivided only on the posterior surface. The basal maxillary sclerite, the cardo, is synscleritous with the submentum, the two forming a Y-shaped structure articulating proximally with the hypostomal area of the head capsule. Distally both cardo and submentum have an articulation with the maxillary basistipes, which bears two elongate setae (BS1, BS2) and a membranous pore (BSa). The following maxillary segment, the dististipes (syn.: palpiger), bears a narrow scleritous plate from which a further seta (DS1) arises. The terminal part of the maxilla is represented laterally by the 3-segmented maxillary palp and medially by the lobarium (syn.: mesal lobe). The relatively broad basal palpal segment bears a short, mediallydirected seta (PA1), while the second palpal segment is devoid of setae. The cone-shaped terminal segment of the maxillary palp bears a sensillum digitiformium medially and 8 very short basiconic sensilla apically. The lobarium, which seems to be fused with the proximal segment of the palpus, is provided apically with 3 sensilla trichodea (ST1-3), 2 sensilla styloconica (LSS, MSS) and 3 sensilla basiconica (CSB, LSB, MSB). Owing to their small size, the occurrence of membranous pores on the proximal palpal segments and the lobarium is uncertain.

Body (Figs 7, 8, 10-13, 18-21, 36-45, 54). The cuticle is covered with minute, droplet-shaped structures (5-7 $\mu \mathrm{m}$ in diameter) each terminating in a slender, pointed process (approx. 5-10 $\mu \mathrm{m}$ in length) giving the whole

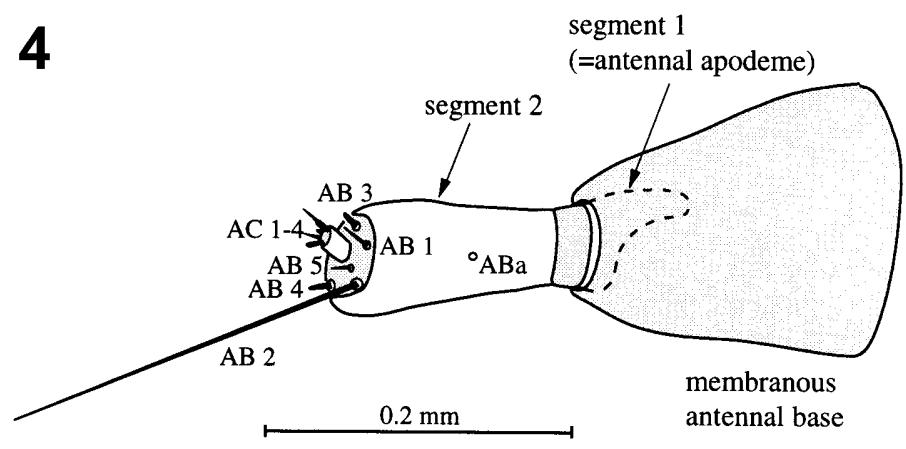

6

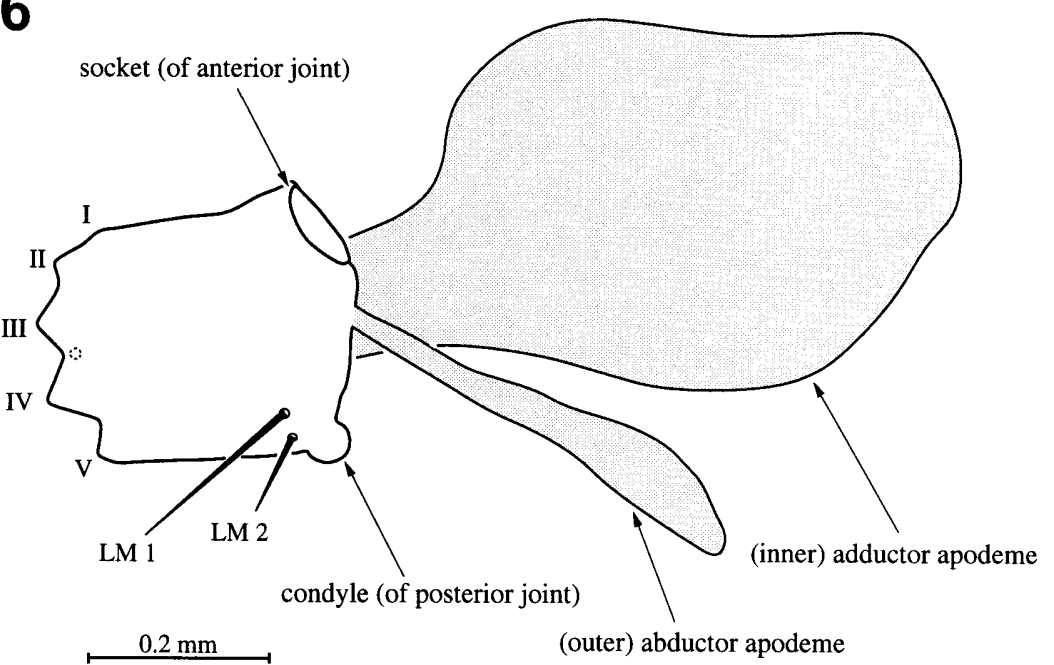

5
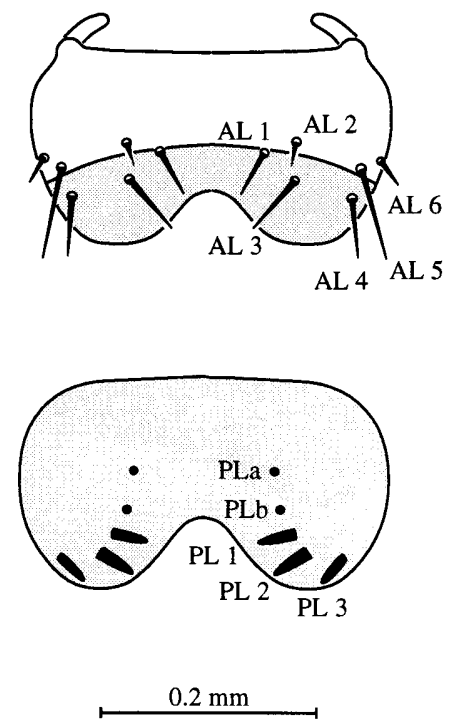

Figs 4-6: 4 - Lateral view of the left antenna of last larval instar of A. infausta (Linnaeus, 1767), showing the various setae and the simple pore $\mathrm{ABa}$. The basal antennal segment is almost completely withdrawn into the membranous antennal base, rendering a determination of the actual length of the apodemal portion difficult; 5 - Labrum of the last larval instar of $A$. infausta (Linnaeus, 1767), anterior surface to the top, posterior (epipharyngeal) surface below. The former bears six pairs of normally developed setae (AL1 - 6), the latter bears three pairs of flattened setae (PL1-3) and two pairs of campaniform sensilla (Pla, Plb); 6 - Left mandible of last larval instar of $A$. infausta (Linnaeus, 1767), lateral view. Five cusps (I-V) of various sizes are recognized, the first one being strongly reduced. The broken circle between cusps III and IV indicates the position of the presumed mandibular gland opening on the medial surface. In addition, the socket and condyle of the mandibular joints are shown together with the outer and inner apodemes. 

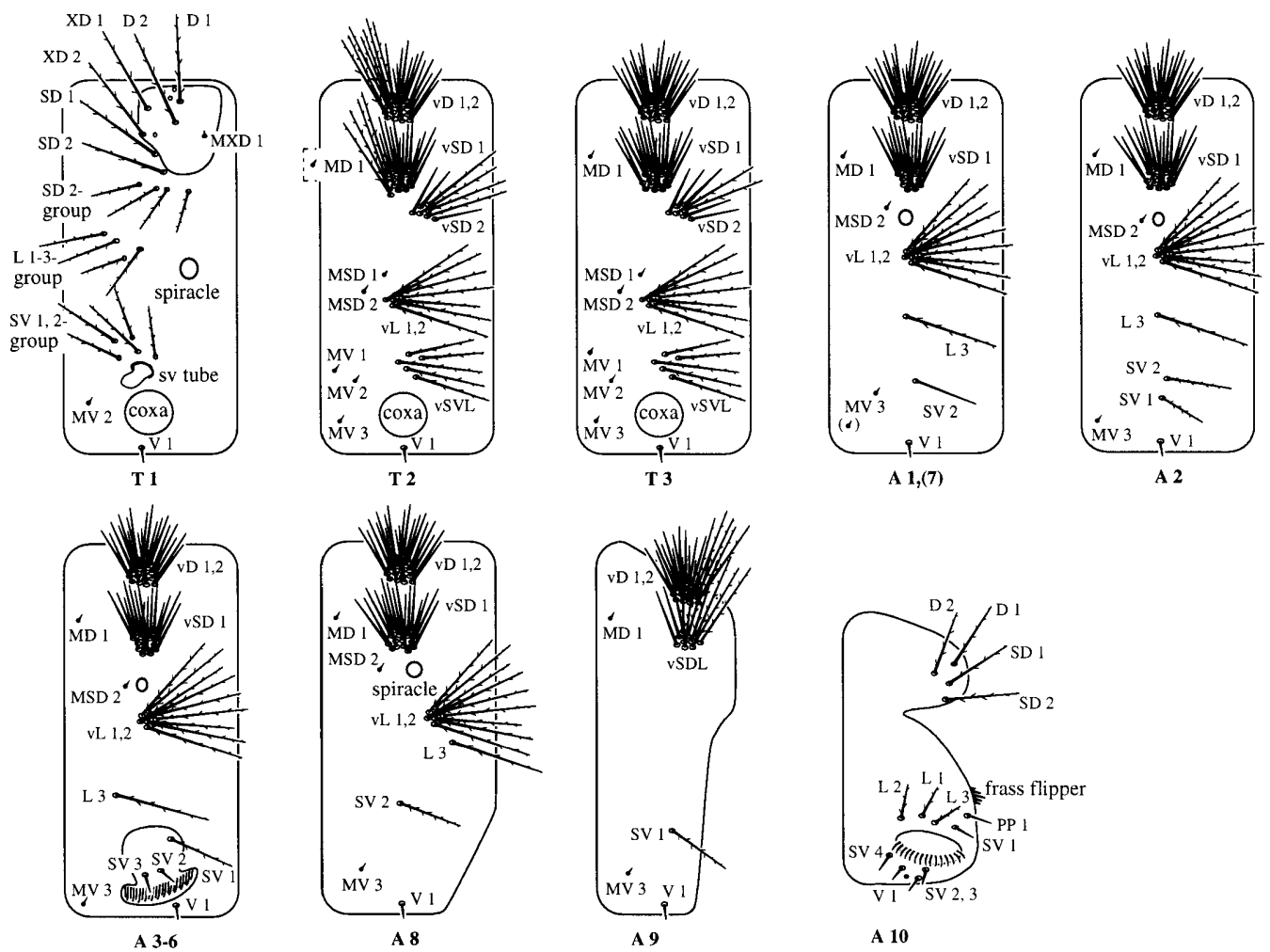

Fig. 7. Setal map depicting the chaetotaxy of the trunk segments of last larval instar of $A$. infausta (Linnaeus, 1767). Two types of macroscopic setae, short stout and elongate plumose setae, can be distinguished. The former are largely concentrated dorsally, the latter occur predominantly in the lateral and ventral regions. On segment T1 the outline of the prothoracic shield, which is provided with 3 pairs of simple pores, is shown. A button-like campaniform sensillum, represented by a black dot, is present ventrally on segment A10. The composite tonofibrillary platelets, present on segments T3-A8, are concealed by the dense tufts of setae arising from vSD1 and therefore not included. A pair of comb-like frass flippers is situated ventrolaterad of the anal opening on segment A10.

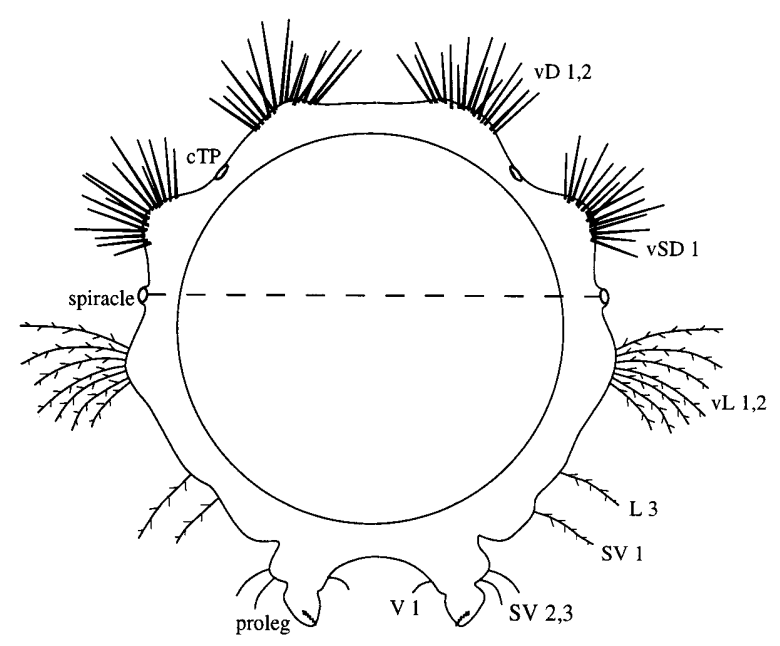

Fig. 8. A typical proleg-bearing abdominal segment of last instar of $A$. infausta (Linnaeus, 1767) larval, separated from the remaining trunk. Halfway between verrucae vD1,2 and vSD1, a large composite tonofibrillary platelet (cTP) is present. The prolegs are well developed, each bearing three unmodified setae (V1, SV2, SV3). The broken line simply serves to stress that the spiracles are situated in the upper half of the trunk. Above this line the setae are stout, below this line the setae are weakly plumose. body surface a shagreen-like texture. Densely scattered between these spinules is a number of elongate spines (around $50 \mu \mathrm{m}$ in length), each of which has a broad rounded base and a single projection that sometimes branches into several subordinate spines. When the spines are unbranched they bear some resemblance to the microsetae described below. However, the base of a microseta is elevated and considerably broader, and the microsetal shaft is comparatively poorly developed. The spiracles, present on segments $\mathrm{T} 1$ and $\mathrm{A} 1-8$, are quite small, those on $\mathrm{T} 1$ and $\mathrm{A} 8$ being distinctly larger. On the prothorax, above the leg, a short subventral tube, that is everted in only a small fraction of the larvae examined, is present. The anatomy of this tube is described in the histological section below. As a further specialization of the body a rounded swelling is situated medioanterior to each proleg. The prothoracic shield is bipartite and fully sclerotized only in the posterior region. A typical anal plate consisting of a single, coherently pigmented structure is lacking. Rather is consists of a number of smaller pigmented dots, probably representing points of muscle attachment. In the SEM, however, the smooth surface of the anal plate contrasts with the shagreen-like texture of the surrounding cuticle. On the paraprocts, the venter of segment A10, a pair of comb-like frass flippers is present ventrolateral to the anal opening. Each frass flipper consists of 
five to seven prongs, the outer ones being distinctly smaller. Dorsal accessory structures associated with the anal opening, such as anal combs or forks, are absent.

Owing to the shagreen-like texture of the surface of the body cuticle, several smooth-surfaced tonofibrillary platelets (TPs), the external markings of muscle attachment sites, are readily recognized on each segment. A particularly large and obviously composite tonofibrillary platelet (cTP) is present dorsolaterally on segments A1-8, that on segment A1 being somewhat smaller and less sclerotized. The cTP is roughly circular in outline and provided with an unevenly sclerotized margin. Being situated immediately above the seta-bearing verruca vSD1, it is often hidden from view. The actual function of the cTP as a site of multiple muscle attachment has been ascertained by both histological examination and dissection of ethanol-fixed larvae. On segment T3, a similar structure is found. However, the metathoracic cTP is only weakly developed and positioned behind (instead of dorsad to) verruca SD1. On segment T2, a typical cTP is absent.

Chaetotaxy of the body (Figs 7, 8, 10, 11-13, 38-40, $42,44,46,47,54-56$ ). In contrast to the head capsule, where only primary setae are found, there are several warts with dense tufts of secondary setae present at primary setal locations on the body segments. These structures, the verrucae, are indicated by adding the prefix " $v$ " to the primary seta symbols. Two different types of setae are encountered. Whereas type I setae are rigid, strongly sclerotized and smooth, type II setae are softer and weakly plumose. Setae of the latter type are not sclerotized/melanistic at all and hence fairly difficult to see without using a SEM. Principally, type I setae are found in the dorsal region above the spiracles, whereas type II setae are predominant in the ventral region below the spiracles (Fig. 8). However, on the thorax and abdominal segment A9 the weakly plumose setae (type II) also extend to the dorsal region (Fig. 7).

On the thoracic segment T1, well-defined verrucae are absent. The prothoracic shield bears at least 6 elongate, weakly plumose setae borne on prominent bases, probably representing setae D1 and D2, XD1 and XD2, as well as SD1 and SD2. Up to 6 further weakly plumose setae, slightly shorter and with smaller bases, may also be present. Below subdorsal seta SD2 a small group of 4, 5 or sometimes 6 setae, here designated the SD2-group, is regularly encountered. The lateral setae are represented by a group of mostly 4 setae, here referred to as the L1-3-group. Subventrally, 5 type II setae, together constituting the SV1,2-group, are present between the prothoracic spiracle and the coxa, i.e. directly above the sv tube. The prothoracic microseta MV3 is absent. On the mesoand metathorax, the verruca vSVL is provided with secondary setae that are probably derived from setae SV1 and L3. On segments T2, T3 and A1-8 three verrucae, $\mathrm{vD} 1,2$ on the purple band, $\mathrm{vSD} 1$ on the white patches within the black dorsolateral band and $\mathrm{vL} 1,2$ on the white patches within the lateral yellow ground colour, occur in very similar positions throughout. Obviously, verruca vSD1 is derived from the subdorsal seta SD1, rather than from the dorsal seta D2. Similarly, verruca vSD2 on the meso- and metathorax is obviously derived from a secondary subdorsal seta SD2, not from the subdorsal seta SD1. These conclusions are primarily based on the relative position of these verrucae to microseta MD1, which is here assumed to be consistently situated in line or above the SD setae. This interpretation is corroborated by the fact that a secondary SD2 seta is found on the abdominal dorsum of certain chalcosiines (Yen \& Yang, 1997: 245 , fig. 3 A) and also by the ontogenetic changes in setal arrangement, which have been followed in Zygaena trifolii (Esper, 1783) (Tremewan, 1985: fig. 53).

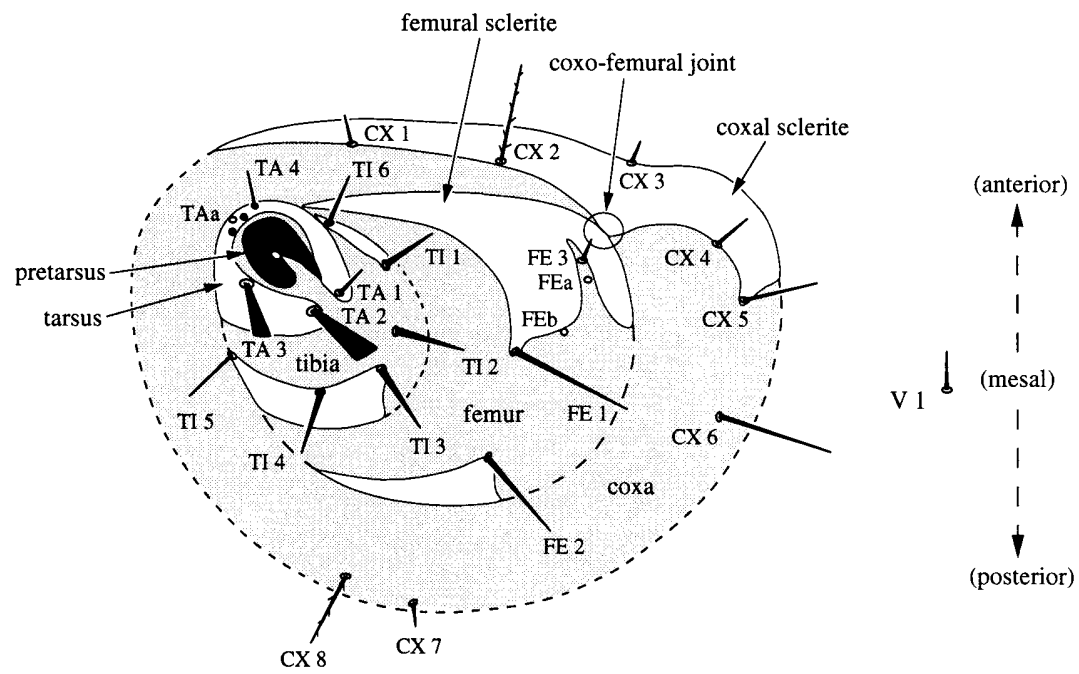

Fig. 9. Right thoracic leg of last larval instar of $A$. infausta (Linnaeus, 1767), ventral view. For better orientation, the ventral midline, indicated by a broken line with arrows, has been included. All setae and simple pores are shown, except for pore TIa that is additionally present on the tibia. The axial seta on the pretarsus is represented by a white oval spot. A pair of button-like structures, presumably representing campaniform sensilla (indicated by black dots), is present on the outer tarsal tip. 


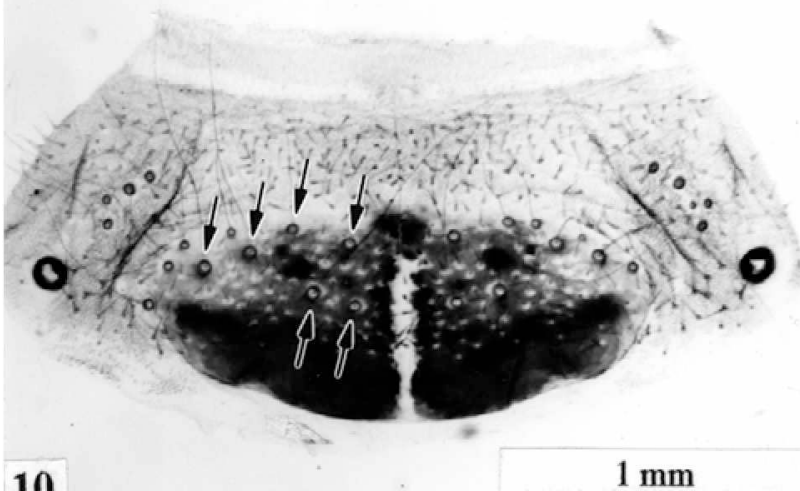

10

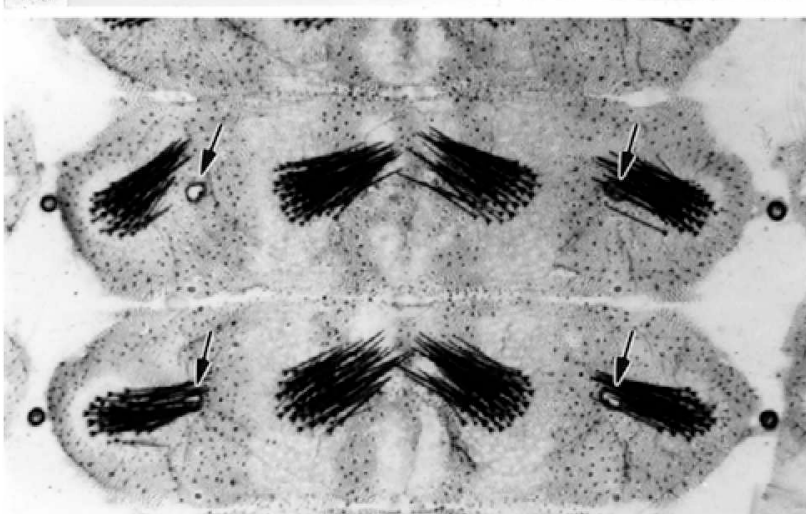

12

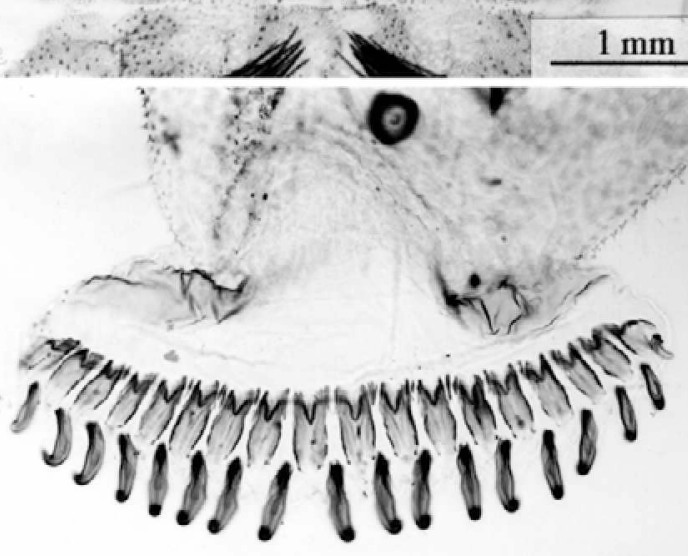

14

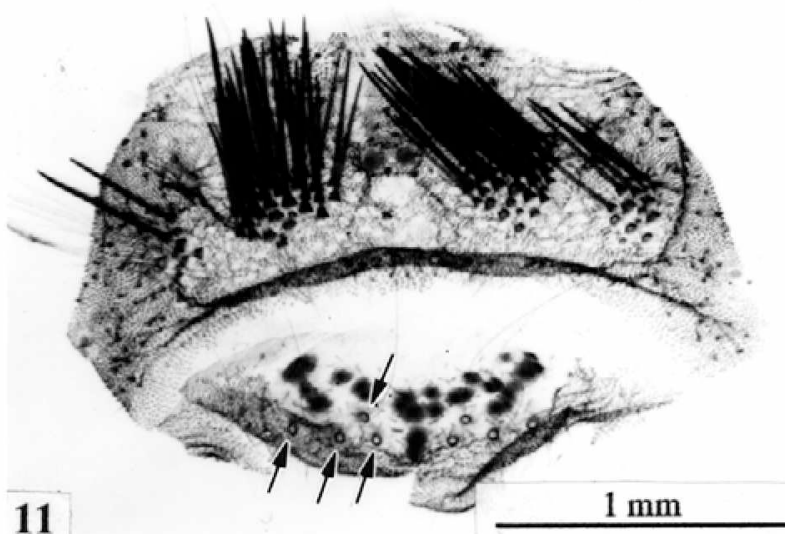

11

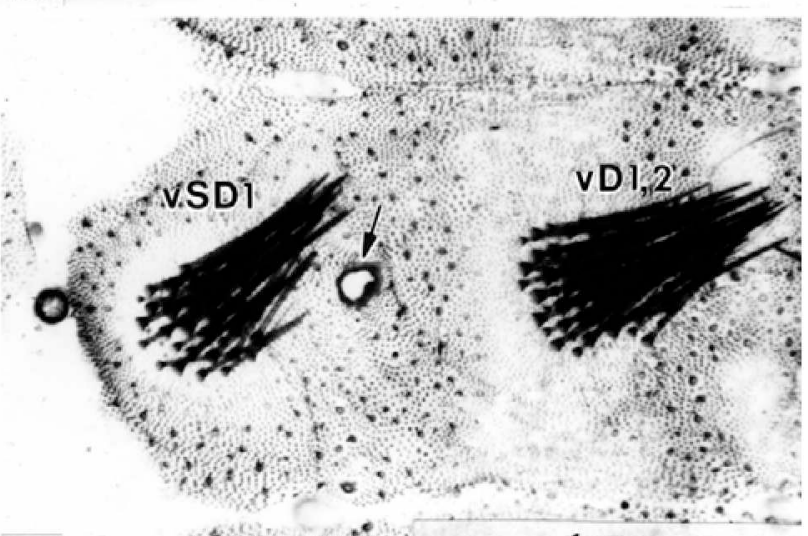

13
$1 \mathrm{~mm}$

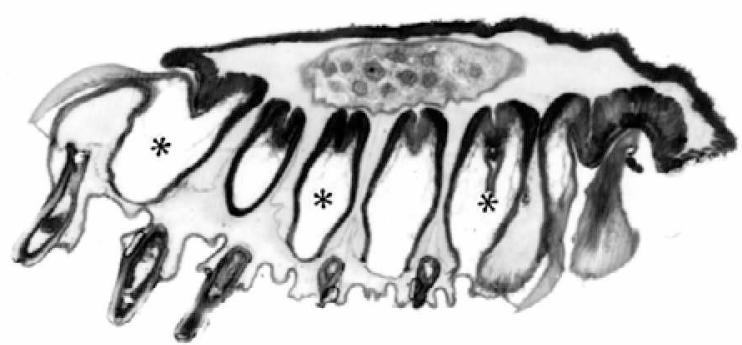

\section{$1 \mathrm{~mm}$}

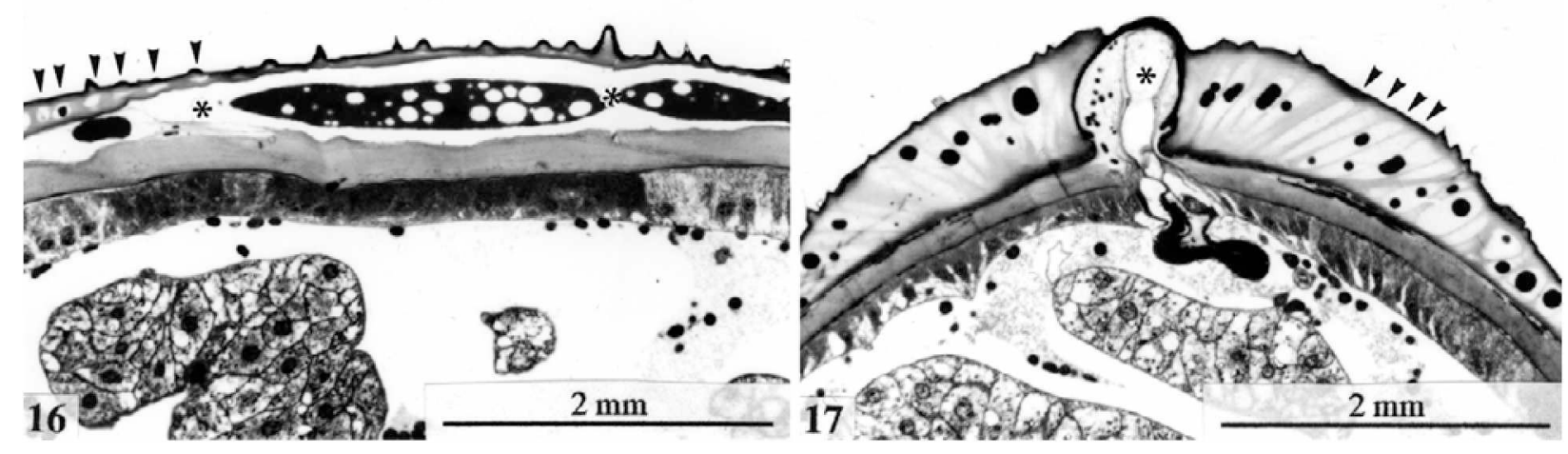


Figs 10-17: Various morphological and anatomical structures of last larval instar of A. infausta (Linnaeùs., 1767). 10 - Slide mount of the prothorax, anterior to top, dorsal view. The prothoracic shield is paired and fully sclerotized only in the posterior region. 6 primary setae (D1, D2, XD1, XD2, SD1, SD2), the bases of which are indicated by arrows, are present on either side of the shield. The primary setae are flanked by 4 pairs of secondary setae, the bases of which are distinctly smaller. The pores and microseta MXD1 are not discernible. Laterally, there are distinct spiracles; 11 - Slide mount of abdominal segments A9 and A10, anterior to top, dorsal view. On segment A9 the verrucae vD1,2 and vSDL as well as a pair of paramedial tonofibrillary platelets are present. Segment A10 is devoid of a well-defined anal plate, but several dark markings, possibly representing points of muscle attachment, are present. Immediately below (morphologically behind) the markings, 4 primary setae (D1, D2, SD1, SD2), the bases of which are indicated by arrows, are situated on either side; 12 - Slide mount of two proleg-bearing abdominal segments, anterior below, dorsal view. On both sides of the dorsal midline the verrucae vD1,2 and vSD1 can be seen. Large composite tonofibrillary platelets, indicated by arrows, are always present between these verrucae, but often hidden under tufts of setae. Laterally, small circular spiracles are apparent; 13 - Slide mount of a proleg-bearing abdominal segment, dorsal view. The large composite tonofibrillary platelet (cTP), indicated by an arrow, is shown at higher magnification, detail of preceding figure; 14 - Slide mount of the distal part of a typical abdominal proleg. Above the crochets, which are arranged in an undivided uniordinal mesoseries, a row of sclerotized "basal plates" is present. The crochets and the plates occur alternately, i.e. in a zipper-like fashion; 15 - Longitudinal section through the distal part of an abdominal proleg. The "basal plates" are represented by cuticular invaginations (indicated by asterisks), bearing a cone-like proximal invagination; 16 - Cross section through the paramedian dorsal integument of a prolegbearing abdominal segment. A large, secretion-filled cuticular cavity covers most of the dorsal region (asterisks). Laterally the tapering large cavity is overlain by several small cavities (arrowheads); 17 - Cross section through verruca vD1,2 of a prolegbearing abdominal segment. Within the outer layer of the two-layered cuticle a number of narrow elongate cuticular cavities (arrowheads) are present. Among the cavities, each of which is filled with a darkly stained droplet, the voluminous rounded base of a sensory seta, whose shaft lies outside the plane of the section, can be seen (asterisk).

On segments A1 and A7, seta SV1 is normally absent, although it has sometimes been found to occur unilaterally on segment A7. On segment A1, the microseta MV3 is present in a position that is situated surprisingly far dorsal. On segment A8, seta SV1 is absent and seta L3 is located far dorsal and hardly set off against vL1,2. On segment A9, the verrucae vSD1 and $\mathrm{vL1,2}$ are indistinguishably fused with seta L3 to form the single composite verruca vSDL. Interestingly, vD1,2 and vSDL exhibit a mixture of both types of setae. On segment A10 the anal shield is provided with 4 , sometimes 5 weakly plumose setae. Setae SV2 and SV3 are situated ventrally. All setae are firmly attached to the body, i.e. they are not deciduous. It should be noted that a full set of body microsetae is present, the absence of MV3 on the prothorax being the only recognized exception. A total of 3 pores are present on the prothoracic shield, the dorsal one being distinctly smaller than the other two. A button-like campaniform sensillum is situated ventrally on the anal segment.

Thoracic legs (Figs 9, 48-53). The usual three pairs of almost identical legs are present on the thorax. The coxa, which is hardly delimited from the surrounding body cuticle, is largely membranous, except for the elongate and slender coxal sclerite. The latter is confined to the anterior region of the coxa and forms a narrow articulation with the adjoining sclerite of the femur. Eight coxal setae (CX1-8) are restricted to the anterior, medial and posterior regions, while the lateral region is devoid of setae. The setae $\mathrm{CX} 2$ and $\mathrm{CX} 8$ are weakly plumose, the remaining setae are simple. Femur, tibia and tarsus are each represented by a well-sclerotized cylinder that is membranous only in the medial region. The femur bears three setae (FE1-3) and two pores (FEa, FEb) on the medial surface. Both pores are situated in a cleft of the femoral sclerite. In contrast to the setae FE1 and FE2, which are well-developed, seta FE3 is very small, inconspicuous and often hidden in the deep cleft that is present on the femoral sclerite. The tibia is provided with six stout setae (TI1-6) and a single pore on the outer surface (TIa, not shown in Fig. 9). On the tarsus, two normal setae (TA1, TA4) and two broadly spatulate setae (TA2, TA3) are present. In addition, two dome-shaped structures that may represent campaniform sensilla and a pore (TAa) were found on the outer apical margin. The pretarsus is represented by a strongly sclerotized, hookshaped structure that is subdivided into a base and a terminal claw. In the angle between both, a short axial seta occurs.

Prolegs and anal prolegs (Figs 8, 14, 47, 57-59). The prolegs, confined to segments A3-6, are characterized by longitudinally elongate distal segments bearing crochets that are arranged in an undivided uniordinal mesoseries. Immediately above the crochets, which range from 18 to 22 (mean 19.5 with $\mathbf{n}=15$ ) in number, a row of tooth-like structures, the coronal blisters (Hasenfuss, 1999), is apparent under a SEM, one tooth always occurring above each individual crochet. Furthermore, a row of sclerotized "basal plates", which are actually cuticular cavities (see below), are also present above the crochets. Crochets and tooth-like structures on the one hand and basal plates on the other occur alternately, i.e. in a zipper-like fashion (Figs 14, 15). Each proleg bears three well-developed setae, two on the lateral (SV2, SV3) and one on the mesal (V1) surface. There are no particular differences between the prolegs and anal prolegs, except in the setae.

Histological investigations (Figs 15-17). Transverse, sagittal and horizontal serial sections of proleg-bearing abdominal segments revealed the following anatomical details:

(1) A pair of large cuticular cavities (Fig. 16) is confined to the anterior and posterior dorsal regions of each segment, respectively. The dorsolateral and lateral regions exhibit a number of much smaller cuticular cavities (Fig. 17). Specialized openings connecting the droplet-filled cavities with the exterior are absent. 

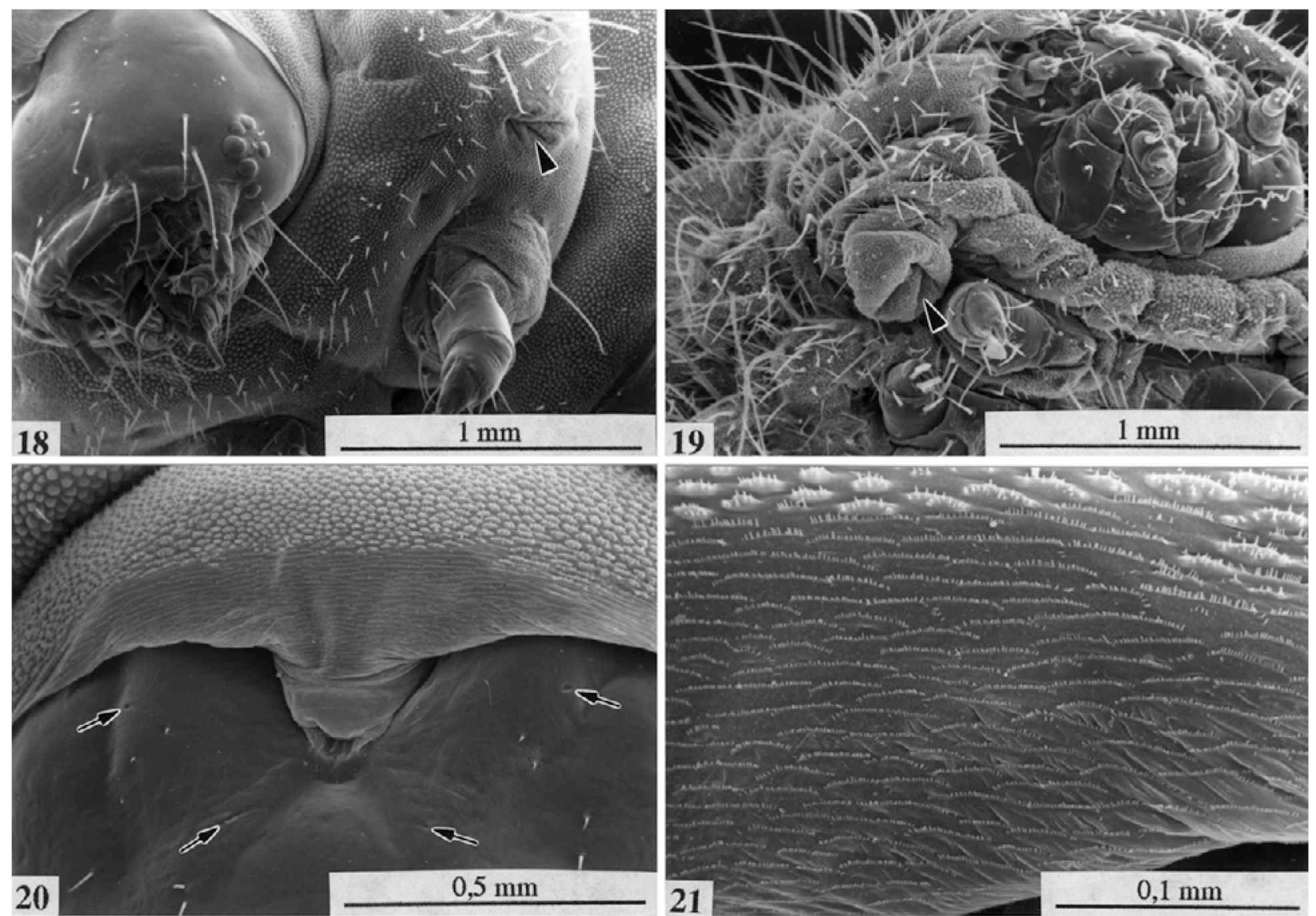

20

$0.5 \mathrm{~mm}$
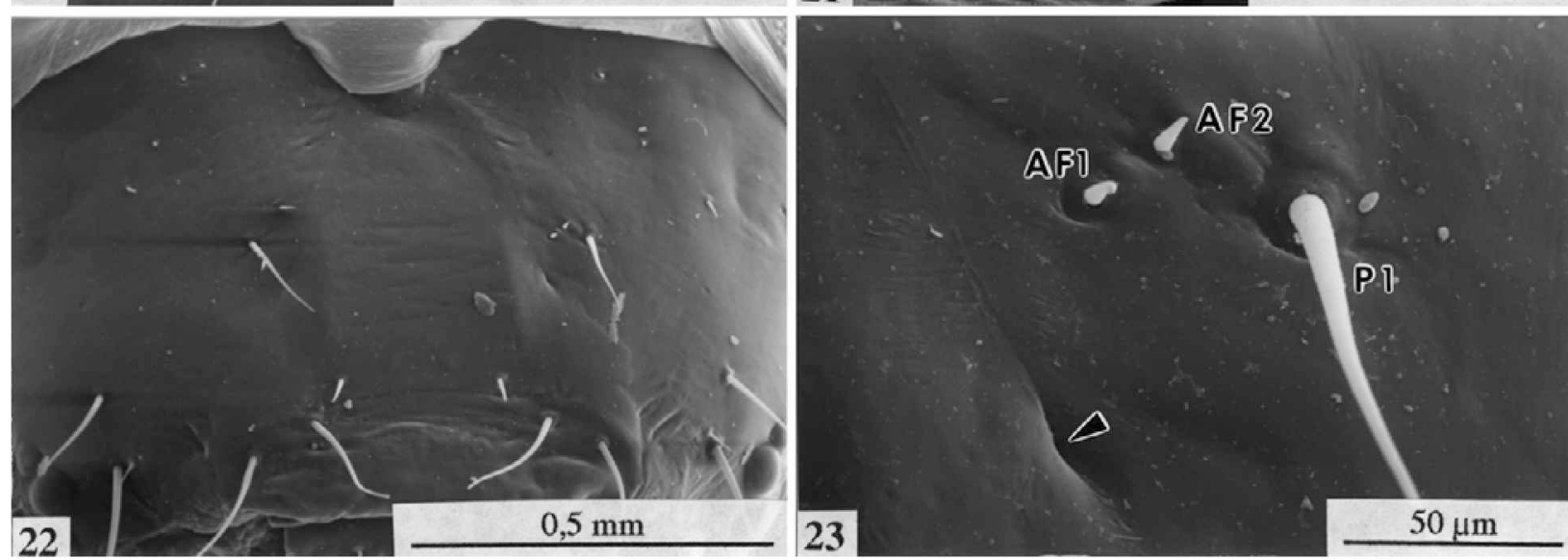

Figs 18-23: SEMs of last larval instar of $A$. infausta (Linnaeus, 1767). 18 - Head capsule and prothorax, with maximally everted head capsule, ventrolateral view. The subventral tube on the prothorax is retracted, but the opening is nevertheless clearly visible (arrowhead); 19 - Head capsule and prothorax, with retracted head capsule, ventrolateral view. The subventral tube on the prothorax (arrowhead) is fully everted; 20 - Mediodorsal region of the everted head capsule, anterodorsal view. Two different types of surface sculpturing of the neck membrane can be distinguished: a narrow anterior region consisting of tightly appressed scale-like plates that are furnished with a terminal row of minute teeth, and a broader posterior region consisting of isolated, slightly elevated structures from which numerous spinulose outgrowths arise in irregular distribution. In addition, the dorsal cranial setae MD1, MD2, MD3, $\mathrm{P} 2$, and AF2 as well as the pores $\mathrm{AFa}$ and $\mathrm{Pb}$ (arrows) are apparent on the head capsule; 21 - Mediodorsal region of the neck membrane, detail of the preceding figure, anterodorsal view; 22 - Head capsule, showing the arrangement of the median cranial setae and pores, anterior view; 23 - Cranial setae AF1, AF2, P1 and the putative anterior tentorial pit (arrowhead), detail of the preceding figure.

(2) The large, composite tonofibrillary platelet (cTP) is a rather simple cuticular structure. It is characterized by a circular sclerotization to which a number of muscles are attached.
(3) The so-called "basal plates", situated above/between the crochets (Fig. 14), proved to be cuticular invaginations that are characterized by a heavily sclerotized internal lining (Fig. 15). 

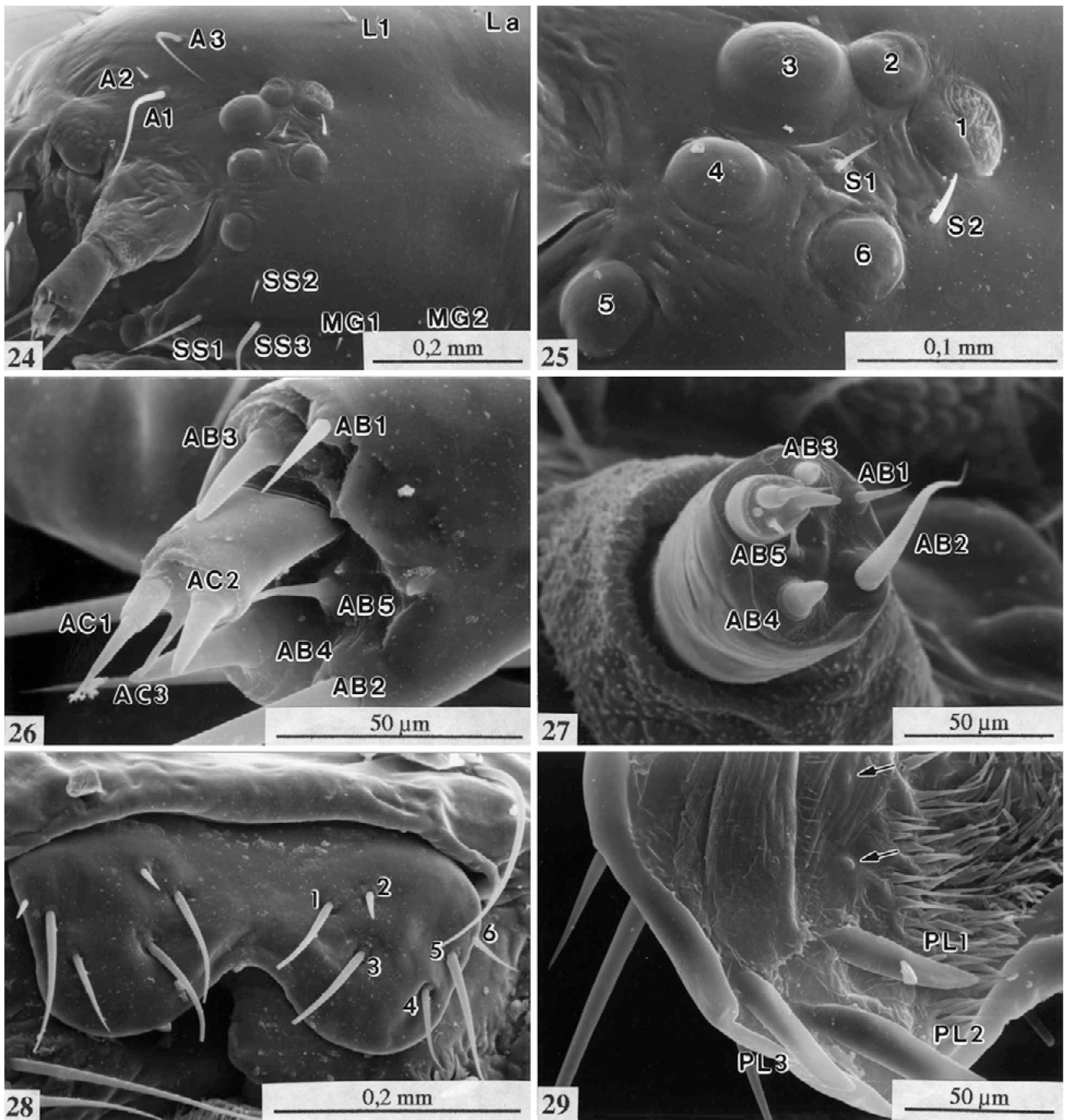

Figs 24-29: SEMs of last larval instar of A. infausta (Linnaeus, 1767). 24 - Head capsule, showing the six stemmata, the antenna, as well as the arrangement of several cranial setae, lateral view; 25 - Stemmata 1-6 with the stemmatal setae (S1, S2), detail of the preceding picture; 26 - Antennal setae, ventrolateral view; 27 - Antennal setae, ventral view; 28 - Labrum with the labral setae (AL 1-6), anterior view; 29 - Left side of the epipharynx, showing the stout setae PL1, PL2, PL3 and the campaniform sensillae PLa, $\mathrm{PLb}$ (arrows). The inner part of the epipharynx is set with medially directed spinules.

(4) The epithelium of the prothoracic subventral tube is simple and flat, not exhibiting any indication of secretory activity. The lumen of the artificially everted tube is filled with haemolymph and a single retractor muscle is present.

\section{DISCUSSION}

The larvae of Zygaeninae use cyanogenesis for their defense. Considerable amounts of the cyanoglucosides linamarin and lotaustralin (as well as a yet unspecified protein fraction) have been detected in cuticular storage chambers (Naumann et al., 1999: 56-60 and references therein). Upon disturbance, cyanogenic secretions are released from these chambers via specialized openings (Franzl \& Naumann, 1985). Enzymatic break-down of linamarin and lotaustralin results in the emission of highly toxic hydrocyanic acid (HCN). However, in A. infausta the cuticular chambers are devoid of external openings and it was not possible to rupture the cuticle experimentally. Such closed cuticular chambers presumably serve to reduce the amount of free cyanoglucosides (and possibly other toxic components) in the larval haemolymph. Arguably, these structures do not protect the larvae 

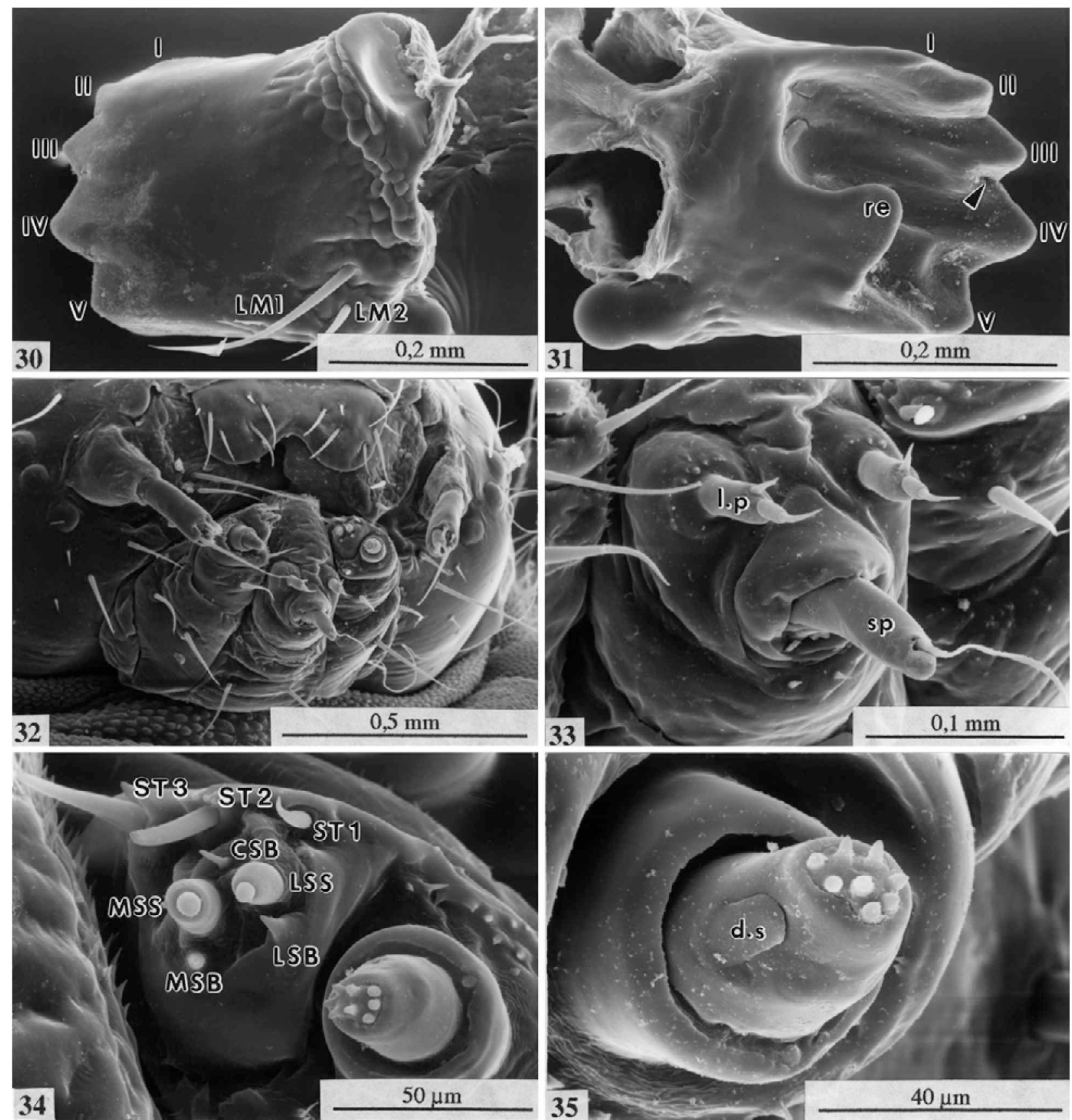

Figs 30-35: SEMs of last larval instar of A. infausta (Linnaeus, 1767). 30 - Left mandible, lateral view. Five terminal cusps (I-V), the socket and part of the condyle of the mandibular articulation and the two setae LM1, LM2 are apparent. Note that cusp I is strongly reduced; 31 - Left mandible, medial view. Five terminal cusps (I-V), the rounded elevation (re) and the putative opening of the putative mandibular gland (arrowhead) are apparent; 32 - Ventral region of the head capsule with the mouthparts and antennae, ventral view; 33 - Prelabial region with the unpaired spinneret (sp), from which a silk thread protrudes, and the labial palps (1.p), detail of the preceding picture; 34 - Lobarium (left) and maxillary palp (right), ventral view; 35 - Maxillary palp, with a median digitiform sensillum (d.s) and 8 terminal basiconic sensilla, medioventral view.

against some predators, like haemolymph-sucking Hemiptera. However, the concept of inclusive fitness can be used to explain why the death of an unpalatable or poisonous larva might still be relevant to its siblings, given the ability of the predator to learn to avoid conspecific host larvae. The latter hypothesis is in accord with the fact that in $A$. infausta the eggs are laid in large batches, although the larvae are not strictly gregarious. The aposematic coloration of the last larval instar may serve to warn potential predators. On the other hand, the bright apose- matic coloration of larvae that indulge in cryptic feeding by means of a small retracted head capsule appears contradictory. Possibly, the protective function of cryptic feeding is only effective in the dull-coloured pre-final instars.

Apparently, mechanical protection also forms part of the complex larval defensive system. While keeping $A$. infausta larvae in the laboratory, we noticed that when fully grown larvae come into contact with sensitive regions of human skin, small pustules that itch appear 

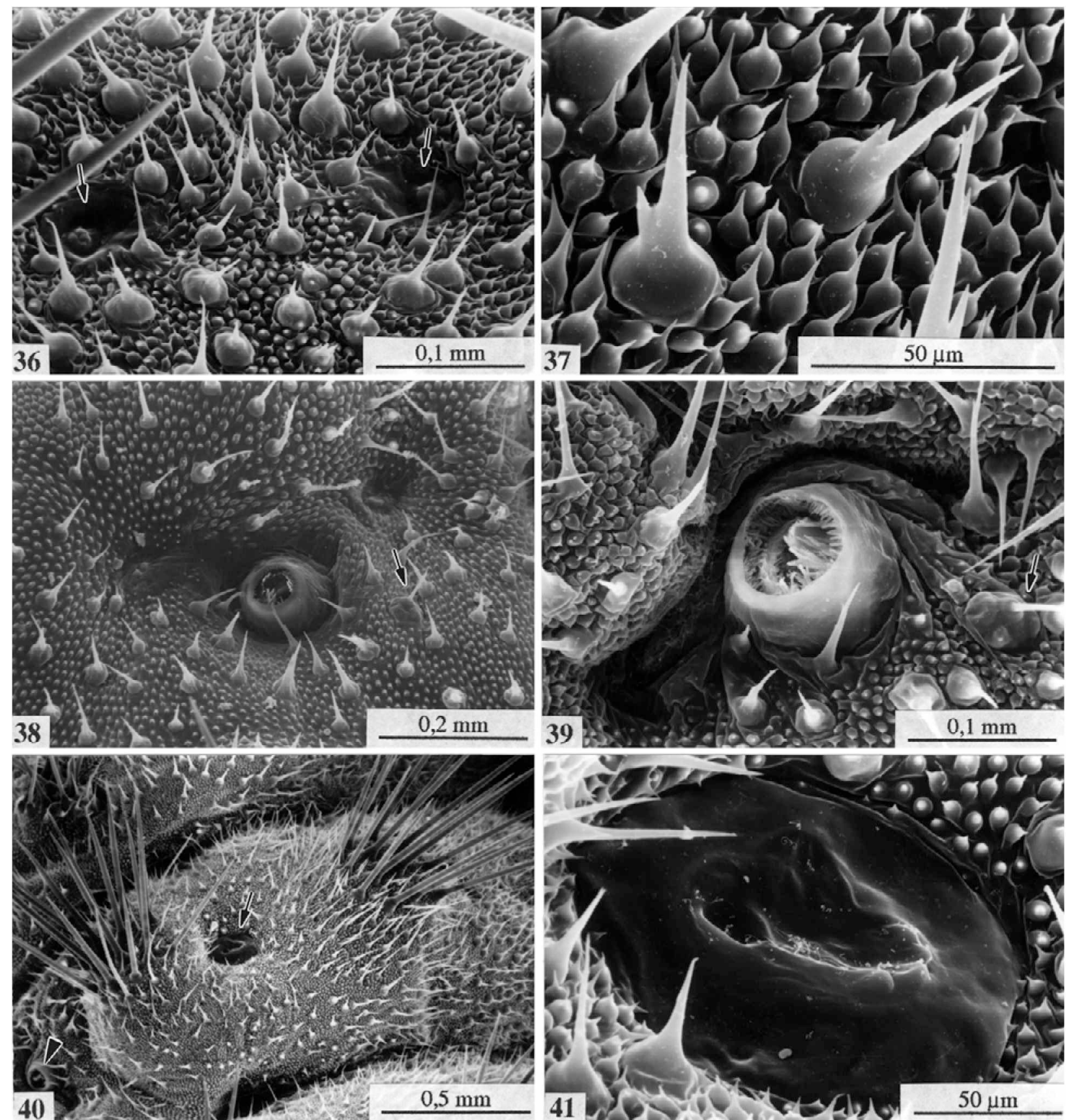

$0,5 \mathrm{~mm}$

Figs 36-41: SEMs of last larval instar of $A$. infausta (Linnaeus, 1767). 36 - Mediodorsal region of abdominal segment A3. The surface sculpturing shows pointed outgrowths of two size classes and a pair of paramedian tonofibrillary platelets (arrows); 37 Dorsal region of abdominal segment A2, showing details of spinulose surface sculpturing. Whereas the small spinules are simple, the larger spines are often branched; 38 - Spiracular region on the right side of abdominal segment $\mathrm{A} 3$, lateral view. The microseta MSD2 (arrow), recognized by its large elevated base, is present in front of the spiracle; 39 - Detail of the spiracle and microseta MSD2 (arrow) on abdominal segment A2, anterior to right; 40 - Dorsolateral region of abdominal segment A2, showing the spiracle (arrowhead), the subdorsal verruca vSD1 (left), the large composite tonofibrillary platelet (arrow), and the dorsal verruca vD1,2 (upper right) caudolateral view; 41 - The large composite tonofibrillary platelet (cTP) on abdominal segment A2, detail of the preceding picture.

within a few minutes. Presumably, these slight irritations, which last for about 30 minutes, are caused by the rigid setae that are present on vD1,2 and vSD1 (see Delgado Quiroz, 1978). The weakly plumose setae occurring on the lateral and ventral regions of the body may have a similar function.

Following the above speculations on the functional significance of some aspects of the larval defensive system, those morphological characters of the larva that might potentially convey meaningful phylogenetic information at different hierarchical levels are successively evaluated in the following paragraphs.

The cranial chaetotaxy of $A$. infausta is similar to that of Phauda mimica Strand, 1915. As already expounded by Fänger et al. (1999), the cranial setae AF2, L1, MD1-3, P1 and P2 are displaced ventrally, while the 

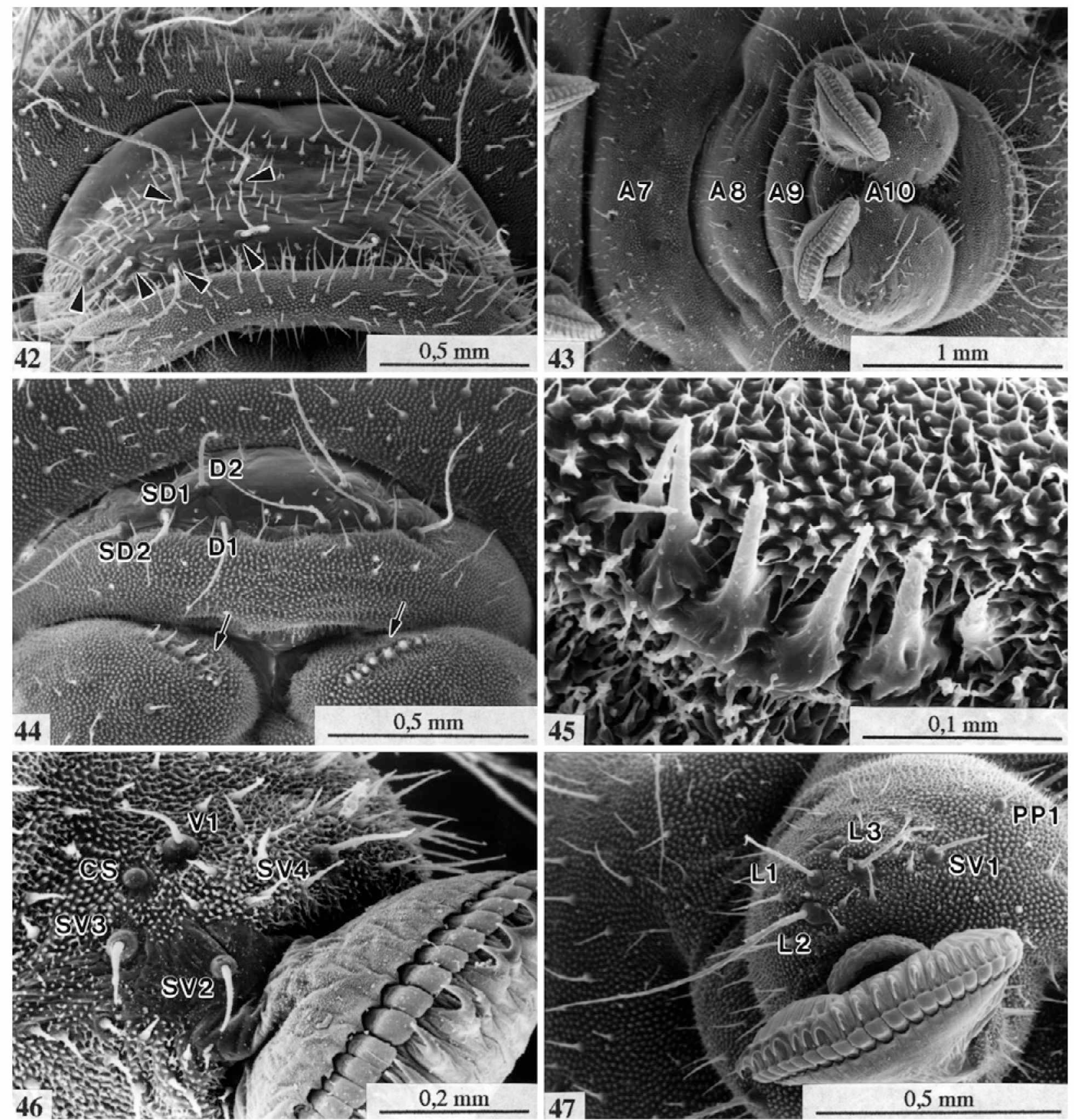

Figs 42-47: SEMs of last larval instar of A. infausta (Linnaeus, 1767). 42 - Prothoracic shield with 6 pairs of primary (arrowheads) and several pairs of secondary setae, anterodorsal view; 43 - Abdominal segments A7-10, ventral view. Segments A7, A8 and A9 are situated behind each other, whereas terminal segment A10 is situated below the penultimate segment A9; $44-$ Perianal region of the terminal abdominal segment A10, caudal view. Below the anal plate, which bears 4 pairs of primary setae (D1, D2, SD1, SD2), there is a pair of frass flippers (arrows) ventrolateral of the rectal opening; 45 - Detail of a frass flipper, consisting of a row of 6 to 7 individual prongs; 46 - Anal proleg with medially adjoining setae (V1, SV2-4) and button-like campaniform sensillum (CS), ventral view; 47 - Anal proleg with laterally adjoining setae (L1-3, PP1 and SV1), ventral view.

setae A2, AF2, L1, MG2, P2 and S1 are short. These specializations, functionally correlated with the marked retractability of the head capsule, will probably prove to be a complex autapomorphic syndrome of the Zygaenoidea. At present, however, information on the lower zygaenoid families Lacturidae and Heterogynidae is not available. In this context it should be noted that the several cranial setae that were earlier claimed to be absent in other zygaenid larvae (Tremewan, 1985; Yen \& Horie,
1997; Yen \& Yang, 1997, 1998), may have been missed as these studies did not use a SEM, which is essential for distinguishing between membranous pores and short setae.

While the plesiomorphic number of six setae (AL1-6) has been retained on the anterior surface of the labrum in A. infausta, only five setae are present in at least some chalcosiine species (Yen \& Yang, 1997: fig. 3c, 1998: fig. 4b). Since the labral setae AL2 and AL6 in $A$. 

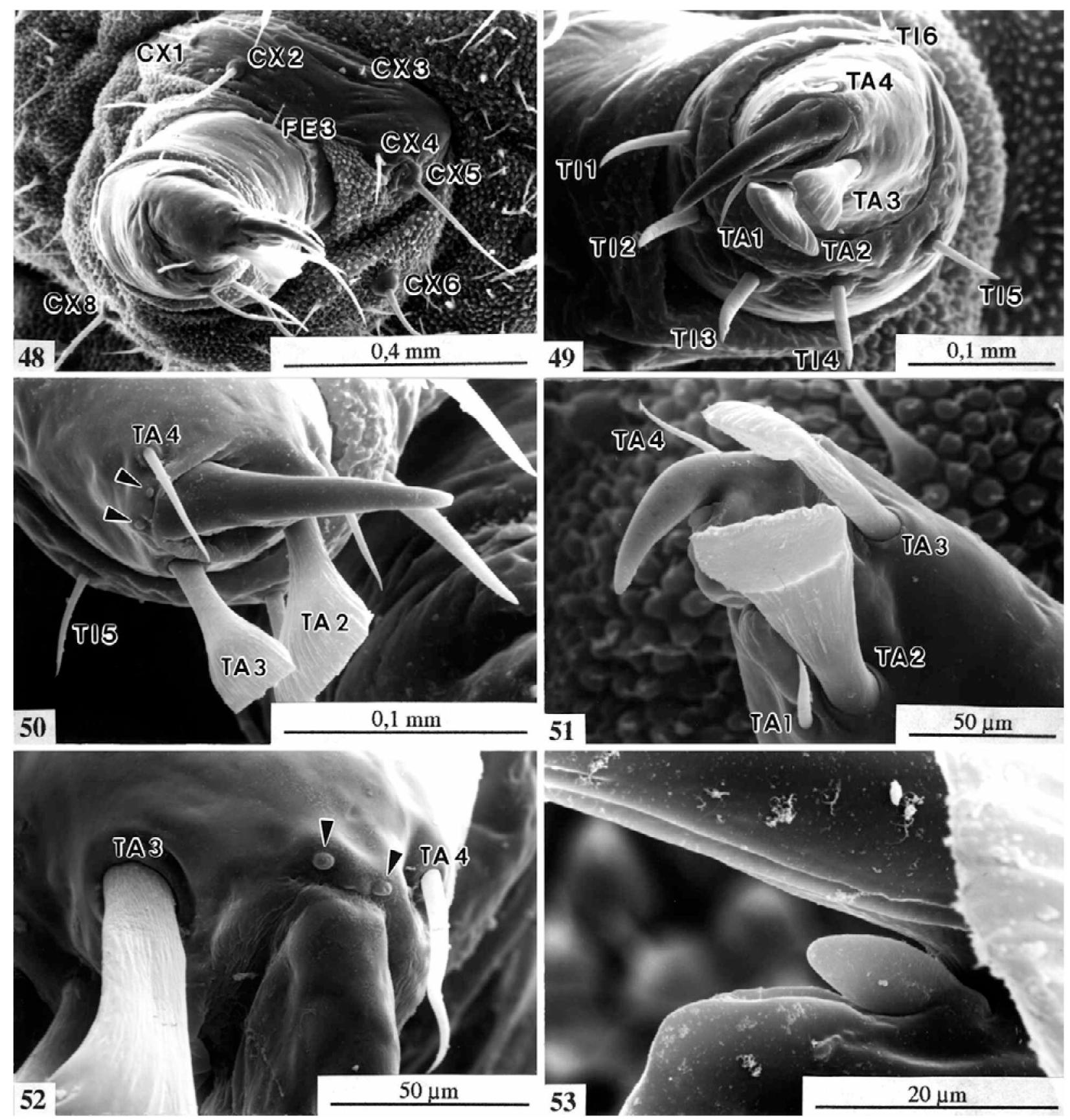

Figs 48-53: SEMs of last larval instar of $A$. infausta (Linnaeus, 1767). 48 - Overview of the right leg of thoracic segment T2, ventral view; 49 - Left leg of thoracic segment T3, showing the arrangement of tibial and tarsal setae, ventral view; 50 - Right leg of thoracic segment $\mathrm{T} 1$, showing the arrangement of the tarsal setae TA1-4 and two putative campaniform sensillae (arrowheads), ventral view; 51 - Left leg of thoracic segment T2, detailing the relative positions of TA1-4, ventroposterior view. Note the broad, spatulate form of setae TA2 and TA3 as well as the presence of a short axial seta in the angle between the pretarsal base and claw; 52 - Detail of the tarsal setae of the right leg of thoracic segment T3, ventral view. Immediately above the pretarsal base, 2 buttonlike campaniform sensillae (arrowheads) are present; 53 - Detail of the axial seta that is present in the angle between the base and claw of the pretarsus, posterior view.

infausta are very short, it seems reasonable to assume that one of these setae was lost during the course of chalcosiine evolution. For unravelling the phylogeny of the subfamily this trait deserves further attention.

A spinulose or shagreen-like surface texture to the body seems to be a widespread phenomenon within the Zygaenoidea and other related superfamilies (Minet, 1991: 72), its absence on the ventral surface of dalcerid and limacodid larvae probably representing a synapomorphic trait
(Epstein, 1996: 25, pl. 6). However, the additional presence of numerous large spines on the larval body has hitherto been found only in A. infausta, possibly indicating a rather limited distribution of this trait.

Large composite tonofibrillary platelets, as seen in $A$. infausta, have so far apparently not been described in any other species. Regarding the considerable size of this integumental modification, even exceeding the spiracles, this trait is unlikely to be common. However, a morpho- 

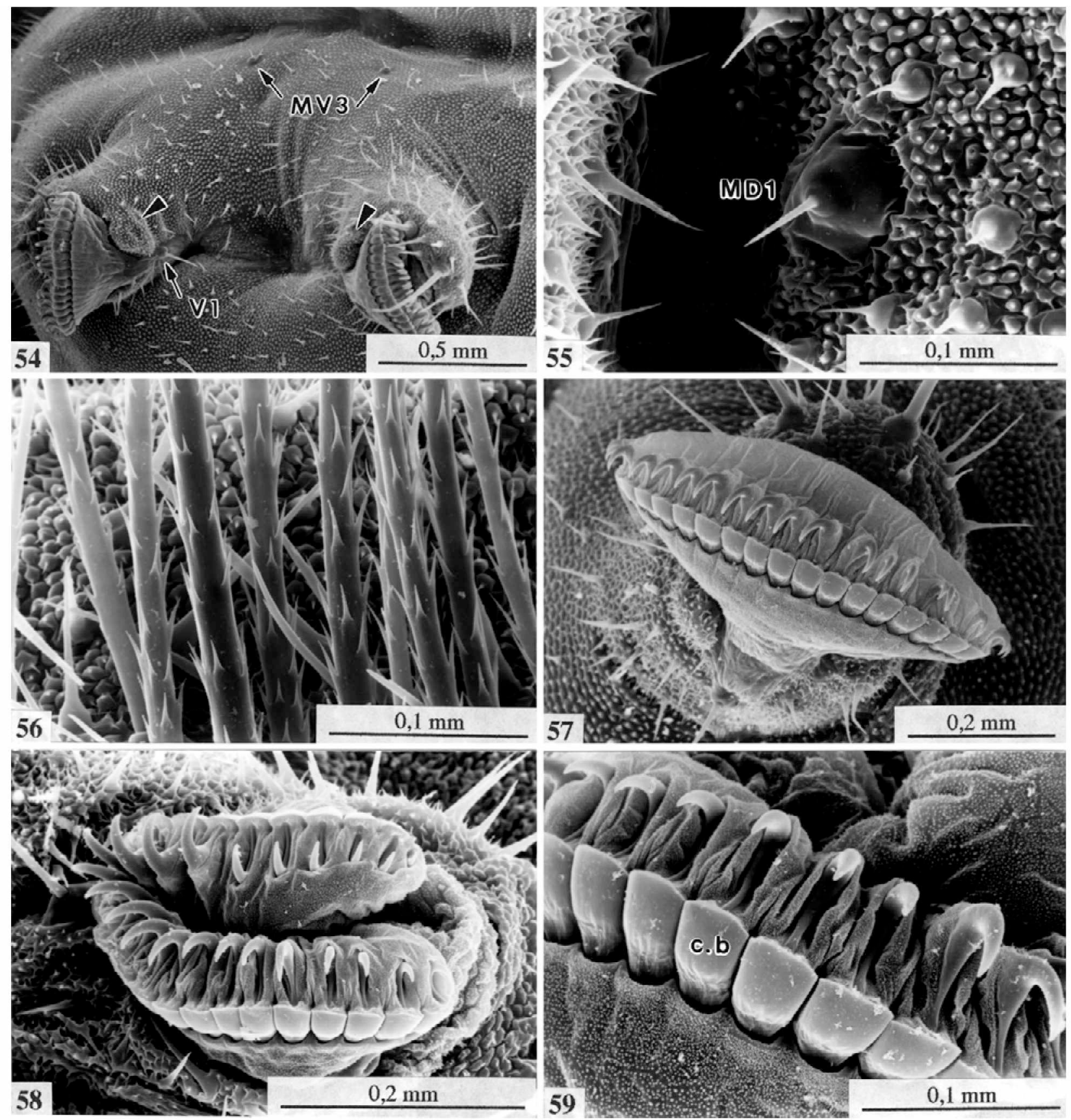

Figs 54-59: SEMs of last larval instar of A. infausta (Linnaeus, 1767). 54 - Ventral region of abdominal segment A5, anterior to top, ventral view. In close vicinity to the ventral setae V1 rounded swellings (arrowheads) are seen at the medial base of the prolegs. In front of the intersegmental furrow separating A4 from A5 a pair of the microsetae MV3 is present; 55 - Detail of microseta MD1 on abdominal segment A3, close to the intersegmental furrow, ventral view; 56 - Group of weakly plumose setae on verruca vL1,2; 57 - Fully expanded elongate proleg of abdominal segment A4, ventral view. Note the row of tooth-like structures, the coronal blisters, that are present immediately below (morphologically above) the crochets; 58 - Partly retracted proleg of abdominal segment A2, ventral view. In this pseudocircular position the inwardly sunken crochets are embedded in a membranous sheath; 59 - Detail of coronal blisters (c.b) and slightly retracted crochets on the proleg of abdominal segment A1, posteroventral view.

logical re-examination of other chalcosiine genera would seem worthwhile.

An eversible prothoracic sv tube, the function of which is unknown, is present in A. infausta and some American procridines (Stehr, 1987: 453, fig. 26.175a,b). However, the eversion of this tube was never observed in a live larva of $A$. infausta and only in a small proportion of the specimens that were immersed in boiling water. Interestingly, a similar eversible tube was also observed recently in fully grown larvae of the chalcosiine Arbudas submacula (Wileman, 1910) (S.-H. Yen, pers. comm.).

An unpaired dorsomedial anal comb (or fork) occurs above the anal opening in the Megalopygidae, Somabrachyidae and some Aididae (Epstein, 1996: 56, figs 278-280). On the other hand, paired frass-flippers, situated ventrolateral of the anal opening, are known to occur in A. infausta as well as in some late instar dalcerids (Epstein, 1996: fig. 277), rendering the phylogenetic 
interpretation of these structures, thought to be used for the removal of frass pellets, difficult.

In addition to the Heterogynidae (Epstein et al., 1999: 170 ), cuticular chambers that are provided with complex opening mechanisms occur throughout the Zygaeninae and Chalcosiinae (Epstein et al., 1999: 173; Naumann \& Feist, 1987; Naumann et al., 1999: 20, 21). Thus, the only known exception to this rule, the occurrence of closed cuticular cavities in A. infousta, is particularly intriguing. Assuming a sister-group relationship between the Chalcosiinae and Zygaeninae, and disregarding for the moment the morphologically insufficiently known Heterogynidae, the evolutionary development of cuticular cavities must have occurred in one of the following ways:

(1.) Cuticular cavities provided with openings represent a chalcosiine/zygaenine synapomorphy and the condition in Aglaope is based on a subsequent closure of the openings.

(2.) Again, cuticular cavities provided with openings represent a chalcosiine/zygaenine synapomorphy. However, in this scenario, Aglaope is not considered to be a member of the Chalcosiinae, but rather the sister group of the Chalcosiinae+Zygaeninae, the presence of closed cuticular cavities being an autapomorphy of the ground pattern of that clade. This unlikely supposition would imply that certain characters shared by Aglaope and the chalcosiines either developed independently in these groups, or developed only once, but were later lost in the stem line of the Zygaeninae.

(3.) Alternatively, closed cuticular cavities might represent a chalcosiine/zygaenine synapomorphy and the cavity openings evolved convergently, once in the stem line of the Zygaeninae and once in the stem line of the Chalcosiinae excluding Aglaope. In this case Aglaope, having retained the primitive character state, would have to be regarded as the sister group of the remaining chalcosiines.

Of course, the possibility that chalcosiines and zygaenines are not sister groups cannot be entirely ruled out. In this unlikely case, cuticular cavities in similar positions must have developed entirely independently in the stem lines of both the Chalcosiinae and Zygaeninae. A detailed comparison of the morphology and distribution of the various types of cavity openings might result in the rejection of some of the above hypotheses.

One of the most troublesome problems in reconstructing the phylogeny of the Zygaenoidea is to assess the arrangement of the body setae. While only primary setae are present in the Lacturidae (Common, 1990: 296), Aididae, Dalceridae and Limacodidae (Epstein, 1996), and also in the isolated genus Phauda Walker, 1854 (Fänger et al., 1999), numerous secondary setae are found in the Himantopteridae (Barlow \& Carter, 1996), Megalopygidae and Somabrachyidae (Epstein, 1996), Epipyropidae and Cyclotornidae (Common, 1990: 305, 308) as well as in most zygaenids (Tremewan, 1985: 87; Naumann et al., 1999: 18). However, complementing the confusion, primary setae also occur in the zygaenine species Pryeria sinica Moore, 1877 (Yen \& Horie, 1997) and in at least some chalcosiines (Yen \& Yang, 1997, 1998). Before a plausible hypothesis can be put forward to account for the evolutionary events that led to the observed character distribution, a detailed comparative investigation on the arrangement of the secondary setae, preferably in conjunction with a broader cladistic analysis, is needed. Even the structure of the secondary setae should be considered, since plumose setae have been found on the body of at least some Zygaenidae (present paper) and Megalopygidae (Epstein, 1996: figs 168, $169,255,257,331$ ).

The subventral seta SV1 was found to be normally absent on segments A1 and A7, while it is well developed on the remaining abdominal segments. In Dalceridae and Limacodidae, on the other hand, seta SV1 is retained on A2-8, although it has been greatly reduced to a buttonlike campaniform sensillum (Epstein, 1996: figs 180, 181, pls 4,5 , described as "fungiform seta"). No information is yet available on the setal arrangement of the first abdominal segment in these groups. Apparently, however, the lack of seta SV1 on segments A1 and A7 is not widespread within the Zygaenoidea.

On abdominal segment A9, the lateral setae L1-3 are absent. Consequently, they either must have been completely reduced or fully integrated into verruca VSD1 to form the composite verruca VSDL, an idea that has been favoured in the present study. As far as is known, other chalcosiine genera still seem to exhibit the typical trisetose condition, although a definite conclusion is hindered by the fact that segment A9 merges with A10 for the most part (Yen \& Yang, 1997: 245, fig. 3 A; 1998: 213, fig. 4 A). The character may tentatively be considered an autapomorphy of the genus Aglaope.

As a plesiomorphic trait an almost complete set of microsetae is retained on the body segments of zygaenid larvae (Tremewan 1985: fig. 53 and present study). The absence of a single microseta on the prothorax, either corresponding to MV2 or MV3, is a remarkable exception that needs further comparative analysis. In contrast, Phauda mimica has recently been shown to lack all microsetae with the exception of MXD1 on the prothorax and MSD2 on the abdominal segments A1-8 (Fänger et al., 1999: fig.7). Apparently, the same condition occurs in the larvae of the limacodid-group (Epstein, 1996: figs 177-181). It remains to be determined whether the loss of body microsetae will prove to be a further synapomorphy between Phauda (and allied genera) and the limacodid group.

The presence of two broadly spatulate setae (TA2, TA3) on the tarsus of the thoracic legs seems to be of particular importance. Whereas two spatulate setae are also known to occur in other zygaenids (Epstein et al., 1999: 172; Hasenfuss, 1999: Fig. 8 B), only a single spatulate seta (TA3) has recently been found in Phauda mimica (Fänger et al., 1999). In contrast, distinctly spatulate setae are absent in the limacodid-group families (Epstein, 1996: figs 225-229, 231-239, 244, 245). Since Phauda (and its allies) seems to be the sister group of the latter families (Fänger et al., 1999), the distribution indicates that either 
one or two spatulate setae were already present in the zygaenoid ground pattern, but were subsequently lost in the stem line of the limacodid group. Evidently, the morphology of the tarsal setae in the remaining zygaenoid families will have to be determined before this point can be settled. Spatulate setae, improving the adhesion to smooth surfaces by means of a thin fluid lipid film (Hasenfuss, 1999), are known to occur on the tarsi of the thoracic legs in a variety of lepidopteran families (reviewed in Miller, 1991: 146, figs 466-492 and Hasenfuss, 1999).

Whereas according to the present findings only two pores are present on the thoracic leg femur of $A$. infausta, three pores $(\mathrm{FEa}-\mathrm{c})$ have recently been claimed to occur on the femur of Phauda mimica (Fänger et al., 1999). However, a re-investigation of the latter species revealed that the structure originally referred to as pore FEa is actually a very short seta (corresponding to seta FE3 of the present paper).

Specialized "basal plates" above the crochets, like those described for $A$. infausta, have been described for Zygaena lonicerae (Scheven, 1777) by Hasenfuss (1999: Fig. 8 E, G as "invaginated crochets") and are used as a distinctive zygaenid trait in a larval key to families (Holloway et al., 1987: 209 and figure on 210). Although they are deeply invaginated structures, they can be seen using light-microscopy, because of their strongly sclerotized exocuticular lining. In contrast, it is necessary to use a SEM to see the coronal blisters above the crochets (Hasenfuss, 1999: Figs 8 F, $10 \mathrm{G}$ ). The latter were tentatively regarded as a zygaenoid autapomorphy (Fänger et al., 1999: 448; Hasenfuss, 1999: 158). Both characters could prove useful when attempting to reconstruct the natural system of the Zygaenoidea.

ACKNOWLEDGEMENTS. The serial sections were prepared in co-operation with H.W. Krenn and C. Wirkner (Zoological Institute, Vienna University) and N.P. Kristensen (Zoologisk Museum, Copenhagen), whose help is gratefully acknowledged. We are indebted to W.G. Tremewan (Truro/Cornwall) and an unknown referee for linguistic refinement of the original manuscript. The study was generously funded by the Deutsche Forschungsgemeinschaft (project $\mathrm{Na}$ 90/9-1).

\section{REFERENCES}

Alberti B. 1954: Über die stammesgeschichtliche Gliederung der Zygaenidae nebst Revision einiger Gruppen (Insecta, Lepidoptera). Mitt. Zool. Mus. Berl. 30: 117-480.

BARLOW H.S. \& CARTER D.J. 1996: A breeding record for Himantopterus fuscinervis Wesmael (Lepidoptera, Himantopteridae). Malay. Nat. J. 150: 27-32.

Common I.F.B. 1990: Moths of Australia. E.J. Brill, Leiden, 535 pp.

Delgado Quiroz A. 1978: Venoms of Lepidoptera. In Bettini S. (ed.): Arthropod Venoms. Springer Verlag, Berlin, pp. 555-611.

EPSTEIN M.E. 1996: Revision and phylogeny of the limacodidgroup families, with evolutionary studies on slug caterpillars (Lepidoptera: Zygaenoidea). Smithson. Contrib. Zool. 582: $102 \mathrm{pp}$.
Epstein M., Geertsema H., Naumann C.M. \& Tarmann G.M. 1999: The Zygaenoidea. In Kristensen N.P. (ed.): Handbookof Zoology 4 (35.1). De Gruyter, Berlin, New York, pp. 159-180.

FÄnger H., Yen S.-H. \& Naumann C.M. 1999: External morphology of the last instar larva of Phauda mimica Strand, 1915 (Lepidoptera, Zygaenoidea). Entomol. Scand. 29: 429-450.

Fletcher D.S. \& Nye I.W.B. 1982: In Nye I.W.B. (ed.): The Generic Names of the Moths of the World 4. 1 pl. British Museum (Natural History), London, xiv + $192 \mathrm{pp}$.

Franzl S. \& NAUMANN C.M. 1985: Cuticular cavities: storage chambers for cyanoglucoside-containing defensive secretions in larvae of a zygaenid moth. Tissue Cell 17: 267-278.

Gómez de AizPuRua C. 1991: Biologia y Morfologia de las Orugas, Part IX, Nymphalidae, Satyridae, Lycaenidae, Zygaenidae. Ministerio de Agricultura, Pasca y Alimentacion, Madrid, 226 pp.

HAsenfuss I. 1999: The adhesive devices in larvae of Lepidoptera (Insecta, Pterygota). Zoomorphology 119: 143-162.

Heppner J.B. 1995: Lacturidae, new family (Lepidoptera: Zygaenoidea). Trop. Lepid. 6: 146-148.

Holloway J.D., BRADLEY J.D. \& CARTER D.J. 1987: IIE Guides to Insects of Importance to Man. 1. Lepidoptera. Natural History Museum, London, $262 \mathrm{pp}$.

KYRKI J. 1984: The Yponomeutoidea: a reassessment of the superfamily and its suprageneric groups (Lepidoptera). Entomol. Scand. 15: 71-84.

Miller J. 1991: Cladistics and classification of the Notodontidae (Lepidoptera: Noctuoidea) based on larval and adult morphology. Bull. Am. Mus. Nat. Hist. 204: 1-230.

MiNET J. 1991: Tentative reconstruction of the ditrysian phylogeny (Lepidoptera: Glossata). Entomol. Scand. 22: 69-95.

Naumann C.M. \& Feist R. 1987: The structure and distribution of cyanoglucoside-storing cuticular cavities in Pryeria sinica Moore (Lepidoptera, Zygaenidae). Zoologica Scr. 16: 89-93.

Naumann C.M., Tarmann G. \& Tremewan G.W. 1999: The Western Palaearctic Zygaenidae (Lepidoptera). Apollo Books, Stenstrup, 304 pp.

ROMEIS B. 1989: Mikroskopische Technik. Urban \& Schwarzenberg, München, $697 \mathrm{pp}$.

SCOBle M. 1992: The Lepidoptera. Form, Function and Diversity. Oxford University Press, Oxford, 404 pp.

SteHR F.W. 1987: Zygaenidae (Zygaenoidea). In Stehr (ed.): Immature Insects (chapter 26). Kendall/Hunt, Dubuque, Iowa, pp. 453-454.

TARMAnN G. 1992: A revision of the Arbudas-complex (sensu Hering 1922) and the description of a new androconial organ (Zygaenidae: Chalcosiinae). Heteroc. Sumatr. 7: 31-77.

TARMANN G. 1994: A preliminary review of the classification of the zygaenid subfamily Procridinae (Lepidoptera). Nota Lepidopterol. (Suppl.) 5: 115-123.

TREMEWAN W.G. 1985: Zygaenidae. In J. Heath \& Emmet A.M. (eds): The Moths and Butterflies of Great Britain and Ireland, vol. 2: Cossidae-Heliodinidae. Harley Books, Colchester, pp. 74-123.

Yen S.-H. \& Horie K. 1997: Pryeria sinica Moore (Lepidoptera, Zygaenidae), a newly discovered relic in Taiwan. Trans. Lepidopterol. Soc. Jap. 48: 39-48.

YeN S.-H. \& YANG P.-S. 1997: Two new genera of Chalcosiinae (Zygaenidae) from eastern Palaearctic Asia. Trans. Lepidopterol. Soc. Jap. 48: 243-263.

Yen S.-H. \& YANG P.-S. 1998: The genus Soritia of Taiwan (Zygaenidae, Chalcosiinae, Chalcosiini). Tinea 15: 207-220. 